NBER WORKING PAPER SERIES

\title{
WHERE DID THE PRODUCTIVITY GROWTH GO? INFLATION DYNAMICS AND THE DISTRIBUTION OF INCOME
}

\author{
Ian Dew-Becker \\ Robert J. Gordon \\ Working Paper 11842 \\ http://www.nber.org/papers/w11842 \\ NATIONAL BUREAU OF ECONOMIC RESEARCH \\ 1050 Massachusetts Avenue \\ Cambridge, MA 02138 \\ December 2005
}

We are above all grateful to Dan Feenberg of the NBER for making it possible for us to access and analyze the IRS micro data files. We are grateful for helpful data, ideas and insights to Michael Harper and Phyllis Otto of the BLS, Robert Brown of the BEA, Carol Corrado of the Board of Governors, Mary Daly, Brad DeLong, Julie P. Gordon, Larry Katz, and Mark Watson. Dan Feenberg and Emmanuel Saez were particularly helpful in providing insights and programs that made possible our analysis of the IRS micro data files. Chris Taylor was our exemplary research assistant. The views expressed herein are those of the author(s) and do not necessarily reflect the views of the National Bureau of Economic Research.

(O2005 by Ian Dew-Becker and Robert J. Gordon. All rights reserved. Short sections of text, not to exceed two paragraphs, may be quoted without explicit permission provided that full credit, including $\odot$ notice, is given to the source. 
Where Did the Productivity Growth Go? Inflation Dynamics and the Distribution of Income Ian Dew-Becker and Robert J. Gordon

NBER Working Paper No. 11842

December 2005

JEL No. D31, D33, D63, E31, I30, J30

\begin{abstract}
$\underline{\text { ABSTRACT }}$
A basic tenet of economic science is that productivity growth is the source of growth in real income per capita. But our results raise doubts by creating a direct link between macro productivity growth and the micro evolution of the income distribution. We show that over the entire period 1966-2001, as well as over 1997-2001, only the top 10 percent of the income distribution enjoyed a growth rate of real wage and salary income equal to or above the average rate of economy-wide productivity growth. Growth in median real wage and salary income barely grew at all while average wage and salary income kept pace with productivity growth, because half of the income gains went to the top 10 percent of the income distribution, leaving little left over for the bottom 90 percent. Half of this inequality effect is attributable to gains of the 90th percentile over the 10th percentile; the other half is due to increased skewness within the top 10 percent.

In addition to its micro analysis, this paper also asks whether faster productivity growth reduces inflation, raises nominal wage growth, or raises profits. We find that an acceleration or deceleration of the productivity growth trend alters the inflation rate by at least one-for-one in the opposite direction. This paper revives research on wage adjustment and produces a dynamic interactive model of price and wage adjustment that explains movements of labor's share of income.

What caused rising income inequality? Economists have placed too much emphasis on "skill-biased technical change" and too little attention to the sources of increased skewness at the very top, within the top 1 percent of the income distribution. We distinguish two complementary explanations, the "economics of superstars," i.e., the pure rents earned by sports and entertainment stars, and the escalating compensation premia of CEOs and other top corporate officers. These sources of divergence at the top, combined with the role of deunionization, immigration, and free trade in pushing down incomes at the bottom, have led to the wide divergence between the growth rates of productivity, average compensation, and median compensation.

Ian Dew-Becker

Department of Economics

Northwestern University

Evanston, IL 60208-2600

i-dew@northwestern.edu

Robert J. Gordon

Department of Economics

Northwestern University

Evanston, IL 60208-2600

and NBER

rjg@northwestern.edu
\end{abstract}




\section{Where Did the Productivity Growth Go? Page 1}

"It's no secret that the gap between the rich and the poor has been growing, but the extent to which the richest are leaving everybody else behind is not widely known .... It's like chasing a speedboat with a rowboat."

- Bob Herbert (2005)

"There is no question that a huge gap has opened up between productivity and living standards .... Not since World War II have productivity and income diverged so sharply."

- Louis Uchitelle (2005)

\section{Introduction}

The first half of this decade has witnessed a sharp contrast between strong output growth on one hand, and slow employment and median income growth on the other. Taken together, strong growth in output combined with weak growth in hours has resulted in the 2001-04 “explosion" in U. S. labor productivity growth, implying an underlying trend in productivity growth faster than any previous sub-period of the postwar era.

Yet who received the benefits of this productivity growth explosion? Median household income fell by 3.8 percent from 1999 to 2004 and grew cumulatively from 1995 to 2004 at an annual rate of only 0.9 percent per year, much slower than the growth rate of nonfarm private business (NFPB) output per hour over the same period of 2.9 percent. ${ }^{1}$ Similarly, the median real wage for all workers grew over 1995-2003 at 1.4 percent per year, less than half the rate of productivity growth. ${ }^{2}$

The failure of the productivity growth revival to boost the real incomes and wages of the

1. Mishel et. al. (2005), Table 1.1, p. 42. Median household income updated from 2003 to 2004 from Leonhardt (2005).

2. Mishel et. al. (2005), Table 2.6, p. 122. Measures of real income and real wages from this source deflate 


\section{Where Did the Productivity Growth Go? Page 2}

median family and median worker calls into question the standard economic paradigm that productivity growth translates automatically into rising living standards, as in this quote from Paul Krugman (1990, p. 9):

Productivity isn't everything, but in the long run it is almost everything. A country's ability to improve its standard of living over time depends almost entirely on its ability to raise its output per worker ... the essential arithmetic says that long-term growth in living standards ... depends almost entirely on productivity growth.

\section{Macro and Micro}

This paper should be read in the spirit of a detective novel, "The Case of the Missing Productivity - Where Did It Go?" Our detective story is divided into two parts, macro and micro. The macro part begins with the standard identity stating that productivity growth equals real wage growth if labor's income share is constant. We begin in Part II by examining aggregate data that compares productivity growth with growth in alternative real wage measures. Then in Parts III and IV we ask how the post-1995 productivity growth acceleration enters into the econometrics of price and wage dynamics. In past incarnations of dynamic Phillips curves, productivity growth has been a minor side show if mentioned at all. The paper provides a new look at price and wage dynamics in order to assess the causes of low inflation in the decade after 1995. In light of high demand in the late 1990s, why was inflation so low? What role was played by the revival of trend productivity growth as contrasted to other beneficial supply shocks? Did the productivity growth slowdown of 1965-79 play a parallel role in creating high inflation in the 1970s? Can dynamic wage and price equations reproduce 


\section{Where Did the Productivity Growth Go? Page 3}

the behavior of changes in labor's income share that have been observed in the data?

The investigation begins with the "mainstream" inflation model that explains price changes by inertia, demand shocks, and supply shocks but does not include wages. A unique contribution of this paper is to bring wages back into the study of wage dynamics and to develop a model including both price and wage equations that include mutual feedback and can capture the effect of changes in trend productivity growth on inflation, nominal wage changes, and changes in labor's income share. In dynamic simulations of the wage-price model, we find that changes in the productivity growth trend had major effects in boosting inflation during 1965-1979 and in slowing down inflation between 1995 and 2005.

The micro section of the paper in Parts V and VI examines the behavior of labor and non-labor income as recorded in the IRS micro data files of the Statistics of Income covering the years 1966-2001. The IRS micro files can be used to determine how much of the real income gain over various periods, e.g., 1966-2001 or 1997-2001, accrue to the median taxpayer and to those at different percentiles from the $10^{\text {th }}$ to the $99.99^{\text {th }}$. The IRS data have the great advantage over the more frequently used CPS data, in that they allow a microscopic view of what is going on inside the upper tenth of the income distribution. We find that increasing inequality inside the upper tenth is as important a source of growing inequality as a higher ratio of incomes at the $90^{\text {th }}$ compared to the $10^{\text {th }}$ percentile.

Our review of the sources of increased income inequality finds that economists have placed too much emphasis on skill-biased technical change and too little on independent factors 


\section{Where Did the Productivity Growth Go? Page 4}

that have pushed down relative incomes at the bottom and raised them at the top. At the bottom it is useful to take a broader perspective that extends back to the 1920s, and we can explain the U-shaped time pattern of inequality by three U-shaped factors - the rise and fall of labor unions, the fall and rise of immigration, and the fall and rise of international trade. At the top we focus on the enormous increase in the income share of the top one percent and even the top 0.01 percent. Part of our analysis applies the "economics of super stars", extending Rosen's original (1981) argument that new technology such as CDs, the internet, and cable TV boosts the earnings premia of superstars. The other part applies to the large part of added income in the upper tail of the income distribution attributable to CEOs and other top corporate officers, where the facts are clear but the interpretations are controversial.

Taken together, the macro and micro parts of our detective story allow us to allocate the cumulative increase in real GDP attributable to the post-1995 acceleration in productivity growth. The macro section allows us to determine how much of the cumulative increase was broadly allocated to all income groups through lower inflation, how much went to nominal labor income, and how much went to nominal non-labor income. The micro section allows us to look within the increased amount of real labor income to determine how much went to the top, middle, and bottom of the income distribution. In the end, we find that only the top 10 percent of taxpayers had gains in real labor income per hour that kept pace with productivity growth over either the 1966-2001 or 1997-2001 periods. The micro section reconciles the paradox that median income lagged so far behind productivity growth while labor's income 


\section{Where Did the Productivity Growth Go? Page 5}

share remained roughly constant, simply because the distributional change caused median income growth to behave so differently than mean growth.

\section{Issues Raised by Macro Data on Productivity and Labor's Share}

We begin by examining data on the interplay between productivity growth and labor's share, using the definition that a constant income share of labor compensation implies that labor productivity grows at the same percentage rate as real labor compensation per hour. How large was the post-1995 acceleration in productivity growth? Did real wages accelerate fully in response, leaving labor's income share intact, or did labor's share decline? How large was the difference among alternative measures of real wage growth?

\section{Decomposing the Difference between Productivity Growth and Median Real Wage Growth}

We begin with a close look at the last four years ending in 2005:Q1. Labor productivity in the nonfarm private business (NFPB) sector over these four years, according to the official data as of July, 2005, registered an annual growth rate of 3.89 percent per year. In contrast, average real hourly earnings in the total private economy increased at an annual rate of only 0.49 percent. We will show that most of this large difference involves data issues, and that the remaining decline in labor's share did not offset an increase in that share during 1995-2001; labor's share was actually higher in 2005:Q1 than eight years earlier. Over a longer period going back to 1954, labor's income share has been virtually constant. 


\section{Where Did the Productivity Growth Go? Page 6}

Data issues largely explain the difference in the four years ending in 2005:Q1 between the 3.89 percent growth in labor productivity in the July data and 0.49 percent growth in real hourly wages. These issues involve: (a) data revisions, (b) the contrast between actual and trend productivity growth, (c) the NFPB sector vs. the total economy, (d) the difference between productivity and real compensation growth, (e) the difference between hourly compensation and average hourly earnings, and (f) the impact of alternative price deflators used to convert nominal wages to real wages.

Data Revisions. The annual revisions of the National Income and Product Accounts (NIPA) in late July, 2005, reduced the growth rate of real GDP over the last few years and raised the rate of inflation. The complementary revisions of the BLS productivity data reduced the annual growth rate of NFPB productivity over the recent four year interval from 3.89 percent per annum to 3.44 percent per annum.

Actual vs. Trend. The distinction between actual and trend productivity growth is illustrated for 1950-2005 in the top frame of Figure 1. The grey-shaded line plots the eightquarter rate of change of NFPB output per hour, and the solid line is a Hodrick-Prescott (HP) trend. ${ }^{3}$ Prior to the recent data revisions, the HP trend reached 3.5 percent per year during the 2003-04 period, but now it barely scrapes 3.0 percent, considerably less than actual productivity growth during 2001-05.

7. The smoothing parameter used for the Hodrick-Prescott filter is 6400 and was chosen in Gordon (2003, pp. 220-1) to avoid too much "bending" of the trend in response to the deep recession of 1981-82. 


\section{Where Did the Productivity Growth Go? Page 7}

Total Economy vs. NFPB. The bottom frame of Figure 1 displays as a solid line the HP

trend for the NFPB sector, copied from the top frame. In contrast the grey line shows the trend for the entire economy. This tracks the NFPB trend quite closely until the late 1980s and then grows more slowly. The total economy trend rises above 2.0 percent in 1999, two years after the NFPB trend, and it only slightly exceeds 2.5 percent during 2002-05. The bottom frame also displays the difference between the two trends, which is very close to zero on average during 1950-85 but then begins to rise, reaching a maximum of $0.60 \mathrm{in} \mathrm{mid-2002.} \mathrm{Understanding} \mathrm{this}$ difference is important both in relation to the behavior of labor's share in the total economy, and also because future potential output growth depends on productivity growth in the total economy, not just that for the NFPB sector.

\section{Productivity, Real Compensation, and Labor's Income Share}

In the top frame of Figure 2 the lower line displays the ratio of NIPA employee compensation in the total economy to NIPA national income, i.e., GDP minus capital consumption and indirect business taxes. Contrary to the widespread impression that labor's share has been squeezed, there was no change in labor's share from 1997:Q3 to 2005:Q1, with a substantial increase in the boom of the late 1990s followed by a reversal in the early years of the current decade. Over a longer period, labor's share has fluctuated over a wider range. There were two big step increases in 1952-54 and especially in 1966-70. There were substantial fluctuations in labor's income share prior to 1984 but little movement since then.

The top line in Figure 2 adds to NIPA employee compensation the labor component of 


\section{Where Did the Productivity Growth Go? Page 8}

proprietors' income, as estimated by the Economic Policy Institute. ${ }^{4}$ Because the share of proprietors' income in total domestic income has declined over the years, and because the labor share of that income has also declined, the overall behavior of labor's income share looks more stable in the upper line in Figure 2. Over the entire interval plotted, labor's share as plotted by the lower line rises from 65.1 percent in 1950:Q1 to 69.5 percent in 2005:Q1. In contrast, labor's share as plotted by the upper line barely rises at all over the same time interval, from 71.8 percent in 1950:Q1 to 72.5 percent in 2005:Q1. Overall there seems little air of crisis in the data on labor's share. Especially when the labor component of proprietors' income is included, the share of labor in domestic income has floated up and down over the decades with no clear trend.

\section{Components of Non-Labor Compensation}

The bottom frame of Figure 2 displays the components of the non-labor capital share of domestic income, which by definition is unity minus the same labor's share concept plotted as the lower line in the top frame. ${ }^{5}$ From bottom to top, the five components are "Government enterprises and transfer payments," then income from rent, above it proprietors' income, then interest, and finally at the top corporate profits. The arrangement is to place the more stable components at the bottom and the more volatile components at the top.

4. See Mishel et. al (2005)., Table 1.24, p. 95. The fraction of total proprietors' income that we use from the Mishel table is linearly interpolated between the selected years that they display.

${ }^{5}$ In the bottom frame of Figure 2 all of Proprietors' income is included in non-labor income. In the top frame the lower line treats all of proprietor's income as non-labor income, and the upper line treats a fraction (ranging from 0.41 to 0.29 ) of proprietors' income as part of labor income. 


\section{Where Did the Productivity Growth Go? Page 9}

The share of the sum of rent and proprietors' income declined from 20.1 percent in 1950:Q1 to a low point of 8.0 percent in 1983:Q3, and then gradually increased to a terminal value of 11.1 percent in 2005:Q1. If this major component of non-labor income declined so much in the postwar era, what emerged to take its place? This was the huge increase in the share of interest income, which evolved slowly during 1960-1980 and then jumped suddenly from 1980 to 1985. The share of interest was a mere 1.4 percent in 1950:Q1, then a slow increase to 6.5 percent in 1979:Q1, then a sharp increase to 10.9 percent in 1986:Q2, and finally a slow slide to 7.2 percent in 2005:Q1. Presumably the increase in the interest income share from 1950 to 1986 combines the gradual increase in the use of debt in the economy, multiplied by a sharp increase in interest rates in the late 1960s, and especially between 1978 and 1981-82 associated with high inflation, the Volcker monetary policy, and the Reagan fiscal deficits.

Much of the current discussion of the failure of productivity gains to spill over to labor income focuses on the buoyant behavior of corporate profits in the past several years. However, the bottom frame of Figure 2 shows that the share of before-tax corporate profits has declined over time. If we examine the ups and downs of the profit share over successive business cycles, the cyclical low point fell from 13.1 percent in 1950:Q1 to 6.9 percent in 2001:Q3, and the cyclical high point fell from 15.4 percent in 1950:Q4 to 11.4 percent in 2005:Q1. ${ }^{6}$ After declining over the earlier part of the postwar era, the profit share has stabilized over the past two decades and was not unusually high in 2001-05. 


\section{Where Did the Productivity Growth Go? Page 10}

The top section of Table 1 displays growth rates of output per hour for the total economy, for the NFPB and private business sectors, and for the four sectors outside of the NFPB sector, namely farms, government, households, and institutions. Growth rates are displayed between "benchmark quarters." 7 The first six columns of Table 1 show annual growth rates between benchmark quarters, the next column shows the average growth rate over the entire 1954-2005 interval, and the final two columns break the 1997-2005 period at 2001:Q1, in order to focus on differences between the 1997-2001 period when the economy was enjoying its extraordinary expansion and 2001-05 when the economy was in recession or recovering from recession.

In the top section of Table 1, we can see that after 1987 residual productivity growth slowed down while NFPB productivity growth increased, accounting for the growing gap between the total economy and the NFPB sector displayed in the bottom frame of Figure 1. Most of this gap can be accounted for by a slowdown in farm productivity growth after 1987, with a small additional contribution from the institutions sector.

Labor's share may evolve differently in each separate sector of the economy. The middle section of Table 1 displays the growth rate of real compensation per hour, deflated by the GDP deflator. Any differences between real wage growth (in the middle section) and

6. The cyclical peak of the profit share in 1997:Q3 (11.6 percent) was almost identical to that in 2005:Q1 (11.4 percent).

7. Benchmark quarters are those when the actual unemployment rate is roughly equal to the NAIRU and is declining through the NAIRU. Benchmark quarters in Table 1 for the period up through 1987 are the same or within one quarter as those used in Gordon (2003). Reflecting lower estimates of the NAIRU 


\section{Where Did the Productivity Growth Go? Page 11}

productivity growth (in the top section) imply changes in labor's income share, as displayed in the bottom section. Over the entire period 1954-2005, differences between real wage growth and productivity growth in the total economy were minimal, with an average growth of real compensation of 2.03 percent per year compared with 1.92 percent for productivity, implying a slight increase in labor's share of 0.11 points per year over the 51 years. Somewhat surprisingly, in light of comments about labor "losing out" from the productivity growth upsurge, labor's share in the total economy actually increased at an annual rate of 0.25 percent over the period 1997-2005.

In the private business sector labor's share exhibited a gradual decline relative to the total economy, with an average annual growth rate over 1954-2005 of -0.26 percent. A notable aspect of Table 1 is that compensation in the "residual" sector increased much faster than productivity, implying a marked increase in labor's income share at an annual rate of 1.28 percent over the full 1954-2005 period. "Baumol's Law" states that labor mobility causes wages to increase uniformly across sectors, so that those sectors with below-average productivity growth (the proverbial "haircuts" and "string quartets") will have real wage growth faster than productivity growth, and hence a positive growth rate of labor's share.

\section{Alternative Wage Indexes and the Role of Price Deflators}

Table 1 compares productivity growth only with growth in a single real wage index, compensation per hour deflated by the GDP deflator. Table 2 displays a wider variety of real 


\section{Where Did the Productivity Growth Go? Page 12}

wage indexes. Compared first are three real wage indexes using the GDP deflator, of which the first is real Compensation per Hour ( $\mathrm{CPH}$ ) in the private business economy, the same index as displayed in the middle section of Table 1. Next is the Employment Cost Index (ECI ), which is a CPI-like index of a market basket of wages which controls for shifts in mix across industries and occupations, both of which plague the CPH. ${ }^{8}$ Third is the BLS index of average hourly earnings (AHE) for production and nonsupervisory workers. Because the real AHE growth rate is often deflated by the CPI in official government publications, we include the bottom rows of Table 2 that allow us to translate different systems of deflation for the alternative wage

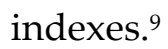

Three themes emerge from Table 2. First, the growth rate of the real CPH is modestly below the growth rate of private sector business productivity over the entire 1954-2005 period and also over the shorter 1997-2005 period. As we have already learned in Table 1, this apparent decline in the private sector labor share in contrast to the stability of the NIPA labor share in Figure 1 is explained by the distinction between the total economy and the private business sector. Labor's share increased steadily in the residual sector but decreased slightly in the private business sector, averaging out for the total economy with a labor share that was almost flat over the past 50 years.

final benchmark quarter is 2005:Q1, the end of the data examined in Table 1.

8. Because the ECI is only available back to 1978, several blank cells appear in Table 2, but we are able to track the growth rate of the ECI measure of the real wage over our sub-intervals starting in 1979.

9. The AHE is deflated by the CPI in the Economic Report of the President 2005, Table B-47. 


\section{Where Did the Productivity Growth Go? Page 13}

The shortfall of $\mathrm{CPH}$ growth relative to productivity growth in the private business sector is minor compared to the shortfall of the other wage indexes displayed in Table 2. For the 1954-2005 interval, the annual growth rate of the shortfall of the real CPH is only -0.25 percent per year, but the shortfall for the AHE is -1.49 percent per year (i.e., 0.80 minus 2.29). When deflated by the CPI-U, the shortfall of the real AHE is - 1.84 percent per year (i.e., 0.45 minus 2.29).

If we shift the time interval to 1979-2005, we can bring the ECI into the comparison, as shown in the far right column. For this interval the private sector $\mathrm{CPH}$ falls short of private sector productivity growth by 0.73 percent per year, while the shortfalls are greater for the ECI (-1.03 percent), the AHE deflated by the GDP deflator (-1.71 percent), and the AHE deflated by the CPI-U (-2.28 percent). What accounts for these discrepancies? Abraham et al. (1999) dealt with the discrepancy between AHE and a series very similar to $\mathrm{CPH}$, and found that much of the difference was explained by the fact that AHE only covers production and non-supervisory workers. Apparently workers not covered by AHE must be seeing much faster wage growth than those covered. The difference between growth in the $\mathrm{CPH}$ and AHE is one aspect of the distinction between median and mean income growth that is a theme of this paper.

\section{The Effect of Changes in the Productivity Trend in a Model of Inflation Dynamics}

We saw in Part II that labor's income share has remained roughly stable over most of the postwar period, and in particular was not significantly lower in early 2005 than in the early 


\section{Where Did the Productivity Growth Go? Page 14}

stages of the productivity revival in mid-1997. This stability in labor's share implies that the post-1995 increase in trend productivity growth exhibited in Figure 1 must have created some combination of slower inflation and faster nominal wage growth. This section of the paper provides a new analysis of the effects of productivity growth on the inflation rate, using and extending the longstanding "mainstream" model of inflation dynamics that was developed in the late 1970s and was last reported upon at BPEA seven years ago (Gordon, 1998). Did the increase in trend productivity growth in 1995-2005 reduce inflation, thus easing the job of the Fed in managing the economy? Did the decrease in trend productivity growth in 1965-1979 raise the inflation rate and thus complicate the job of the Fed in managing the economy of that era that was already buffeted by oil and import price shocks, and by the destabilizing effects of the Nixon price controls? This section begins by presenting the background and specification of the dynamic inflation model, including the role of changes in the productivity growth trend, and then discusses several closely related issues in the literature on inflation dynamics that have arisen recently, including more parsimonious specifications and shifts in parameters, including the slope of the Phillips Curve itself. ${ }^{10}$

\section{The "Mainstream" Model of Inflation and the Role of Demand and Supply Shocks}

The inflation equation used in this paper is similar in most details to the specification developed 25 years ago (Gordon, 1982; Gordon-King, 1982). It builds on earlier work (Gordon,

10. See Gali and Gertler (1999), Gali et al. (2001) and Stock and Watson $(2002,2003)$ for simplified new Keynesian Phillips curves. For discussion of changing parameters see Atkeson and Ohanian (2001) and Tetlow and Ironside (2005). 


\section{Where Did the Productivity Growth Go? Page 15}

1975, 1977) that combined the Friedman-Phelps natural rate hypothesis with the role of supply shocks as a source of direct shifts in the inflation rate. These supply shocks can create macroeconomic externalities in a world of nominal wage rigidity. Since the mid-1990s, this research has built on the work of Staiger, Stock, and Watson $(1997,2001)$ by incorporating time variation in the natural rate of unemployment or "TV-NAIRU." The term "mainstream" model refers to a Phillips Curve that has three distinguishing characteristics - (1) the role of inertia is broadly interpreted to go beyond any specific formulation of expectations formation to include other sources of inertia, e.g., wage and price contracts; (2) the driving force from the demand side is an unemployment or output gap; and (3) supply shock variables appear explicitly in the inflation equation. ${ }^{11}$ The specification can be written in this general form:

$$
p_{t}=a(L) p_{t-1}+b(L) D_{t}+c(L) z_{t}+e_{t} .
$$

Lower-case letters designate first differences of logarithms, upper-case letters designate logarithms of levels, and $L$ is a polynomial in the lag operator.

The dependent variable $p_{t}$ is the inflation rate. Inertia is conveyed by a series of lags on the inflation rate $\left(p_{t-1}\right) . D_{t}$ is an index of excess demand (normalized so that $D_{t}=0$ indicates the absence of excess demand), $z_{t}$ is a vector of supply shock variables (normalized so that $z_{i}=0$ indicates an absence of supply shocks), and $e_{t}$ is a serially uncorrelated error term.

Distinguishing features in the implementation of this model include unusually long lags on the

11. The work of Staiger, Stock, and Watson $(1997,2001)$ is included within the label "mainstream approach." While Gordon's work $(1997,1998)$ adopted their modeling of the TV-NAIRU, their work adopted Gordon's specification of the inflation equation itself, including the specification of demand and 


\section{Where Did the Productivity Growth Go? Page 16}

dependent variable, and a set of supply shock variables that are uniformly defined so that a zero value indicates no upward or downward pressure on inflation.

If the sum of the coefficients on the lagged inflation values equals unity, then there is a "natural rate" of the demand variable $\left(D^{N_{t}}\right)$ consistent with a constant rate of inflation. ${ }^{12}$ The estimation of the time-varying NAIRU combines the above inflation equation, with the unemployment gap serving as the proxy for excess demand, with a second equation that explicitly allows the NAIRU to vary with time:

$$
\begin{gathered}
p_{t}=a(L) p_{t-1}+b(L)\left(U_{t}-U^{N_{t}}\right)+c(L) z_{t}+e_{t}, \\
U^{N_{t}}=U^{N_{t-1}}+v_{t}, E\left(v_{t}\right)=0, \operatorname{var}\left(v_{t}\right)=\sigma^{2}
\end{gathered}
$$

In this formulation, the disturbance term $v_{t}$ in the second equation is serially uncorrelated and is uncorrelated with $e_{t}$. When this standard deviation $\sigma=0$, then the natural rate is constant, and when $\sigma$ is positive, the model allows the NAIRU to vary by a limited amount each quarter. If no limit were placed on the ability of the NAIRU to vary each time period, then the timevarying NAIRU would jump up and down and soak up all the residual variation in the inflation equation (2).

The reduced-form inflation equation (2) includes the gap between the actual unemployment rate and the NAIRU, as well as the lagged dependent (inflation) variable. In addition, five variables are included that are interpreted as supply shocks (the $z_{t}$ variables in (1)

supply shocks and lags thereof.

12. While the estimated sum of the coefficients on lagged inflation is usually roughly equal to unity, that sum must be constrained to be exactly unity for a meaningful "natural rate" of the demand variable to be 


\section{Where Did the Productivity Growth Go? Page 17}

and (2) above), namely the change in the relative price of non-food non-oil imports, the change in the relative price of food and energy, changes in the relative price of medical care, the change in the trend rate of productivity growth, and dummy variables for the effect of the 1971-74

Nixon-era price controls. ${ }^{13}$ Lag lengths were originally specified in Gordon (1982) and have not been changed since then to allow an assessment on the robustness of this approach to 25 years of new data.

Besides the addition of the medical care variable, the other major change in the current inflation equation from the (Gordon, 1998) Goldilocks specification involves productivity growth, the point of departure for the current paper. Here we use the Hodrick-Prescott (H-P) filter as in Figure 1 to define the productivity trend and then define the acceleration or deceleration in the productivity trend as the two-year (eight-quarter) change in the growth rate of the trend, as plotted in Figure 3. Its deceleration into negative territory from 1965 to 1980 might be as important a cause of accelerating inflation in that period as its post-1995 acceleration was a cause of low inflation in the late 1990s.

calculated.

13. The relative import price variable is defined as the rate of change of the non-food non-oil import deflator minus the rate of change of the dependent variable. The relative food-energy variable is defined as the difference between the rates of change of the overall PCE deflator and the "core" PCE deflator. The Nixon control variables remain the same as originally specified in Gordon (1982). Lag lengths remain as in 1982 and are shown explicitly in Table 3. The medical care variable is defined as the difference between the inflation rate of the PCE deflator and the inflation rate for that deflator when medical care spending is deducted from total PCE. The productivity variable is the two year change in the HodrickPrescott filtered trend of productivity using 6400 as the smoothness parameter, as displayed in Figure 3 below. 


\section{Where Did the Productivity Growth Go? Page 18}

\section{Coefficients in Alternative Inflation Equations}

Table 3 displays coefficients or sums of coefficients, significance levels, and simulation results for our basic inflation equation and several other variants estimated over 1962:Q1 to 2005:Q2. What we call the "naive" Phillips curve is displayed in column (1). This contains only the current level of the unemployment rate and four lags on the dependent variable. This equation fits the data poorly; the sum of squared residuals (SSR) is 177.

Column (2) provides the 1998 "Goldilocks" (Gordon, 1998) version of the full mainstream specification in equation (2) above. Included are 24 lags on the dependent variable, the unemployment gap relative to the TV-NAIRU that is estimated simultaneously, and the listed supply shock variables. Comparing the first two columns, the full version in column (2) cuts the SSR by a factor of three, from 177 to 63.

Column (3) shows our preferred specification, incorporating both the productivity acceleration and medical care effect. This version has better summary statistics, all of the coefficients are significant, and the simulation errors show that the equation has little drift over time and has very small mean squared error. The productivity acceleration enters with its first and fifth lags, and these coefficients sum to minus 1.34, indicating that an acceleration in the productivity trend reduces inflation by more than one-for-one. As opposed to the Goldilocks specification using the deviation of actual productivity growth from trend, this variable is highly significant, and shows that changes in the productivity trend have a major impact on 


\section{Where Did the Productivity Growth Go? Page 19}

inflation. ${ }^{14}$

Figure 3 gives an idea of the scale of this impact. The acceleration in the trend hit its peak of 0.46 in 1999, and the effect of the variable near the peak of the last business cycle, between 1998 and 2000, would have been to lower inflation by about a half percentage point. Symmetrically, the deceleration in the trend hit its minimum of -0.40 in 1978 , and this added to the acceleration of inflation in the 1970s by about half a percentage point. As we shall see below in Table 6, these static results greatly underestimate the full impact of the 1995-2005 productivity growth acceleration and the 1965-78 deceleration, because they ignore dynamic feedback through the lagged dependent variable.

\section{The Inflation Equation: Simulation Performance}

While most papers presenting time-series regression results display coefficients, significance levels, and summary statistics, few go beyond that and display results of dynamic simulations. Yet the performance of the inflation equation is driven in large part by the role of the lagged dependent variable, making dynamic simulations the preferable method for testing. To run such simulations, the sample period is truncated ten years before the end of the data interval, and the estimated coefficients through 1995:Q2 are used to simulate the performance of the equation for 1995:Q3 to 2005:Q2, generating the lagged dependent variables endogenously.

Since the simulation has no information on the actual value of the inflation rate and no

14. As in column (2), the sum of the coefficients on the two productivity acceleration terms is highly significant, with a T-ratio of -4.07 . The two individual coefficients are not significant, indicating that they 


\section{Where Did the Productivity Growth Go? Page 20}

error correction mechanism, there is nothing to keep the simulated inflation rate from drifting far away from the actual rate..$^{15}$ The bottom rows of Table 3 summarize the simulation results in two statistics, the mean error (ME) over the 40-quarter simulation period and the root meansquared error (RMSE). The ME reflects the drift of the simulated value away from the actual value, so that in column (1) the naive Phillips curve on average over 1995-2005 has a predicted value of inflation that on average is fully 4.0 percentage points higher than the actual outcome. The 1998 Goldilocks specification in column (2) has a ME of much less, -0.64 points, but still a substantial overprediction of inflation. ${ }^{16}$ In contrast, our preferred specification in column (3) has a miniscule ME of -0.11 for our preferred simulation. The RMSE of the preferred specification is actually substantially lower than the within-sample standard error of estimate (SEE), 0.56 versus 0.65 .

Figure 4 provides a vivid display of the differences among these simulation results for the three specifications summarized in Table 3. The solid black line plots the four-quarter change in the actual PCE inflation rate. To the left of the vertical bar are within-sample predicted values, and the post-sample simulations are displayed to the right of the vertical bar. The naive specification has no clue as to why inflation was so low in the late 1990s, and its

convey the same information. Nevertheless, we include both rather than one or the other, for expositional convenience in Part IV below.

${ }^{15}$ A qualification is that the TV-NAIRU used to calculate the unemployment gap after 1995 is based on data for the full period 1962-2005. This makes little difference, since the TV-NAIRU is almost constant during the 1995-2005 interval.

16. The simulation errors shown in column (2) are calculated with the 1998 specification run on today's data through 2005. The simulation ME reported in the 1998 paper (Table 3, p. 315) was -0.46, but that was 


\section{Where Did the Productivity Growth Go? Page 21}

simulated inflation rate soars up close to 9 percent by 2005. The Goldilocks specification drifts above the actual outcome but by 2005 is still only half a percentage point too high. The preferred specification hugs the actual values with amazing tightness.

The excellent simulation performance has two important implications. First, the equation is more than simply a random walk. The supply shock variables and unemployment gap add a substantial amount of information beyond that from the lagged dependent variable.

Second, the absence of drift in the simulations shows that the equation is stable after 1995.

The price equation is not only stable after 1995, but it is also stable across the full sample. A Chow test for a break at 1983:Q4 cannot reject the null of no break. ${ }^{17}$ Furthermore, when interaction terms are added allowing any of the coefficients to change, none of the sums of interaction terms is significantly different from zero, except for the food-energy effect in the PCE equation.

Atkeson and Ohanian (2001) claimed that the relationship between inflation and unemployment no longer holds. ${ }^{18}$ Their conclusion, however, is entirely dependent on using a random walk to predict inflation. The significance of our coefficients, the performance of our simulations, and the stability of our model over time is at odds with their claim of the instability and structural shift in the Phillips curve.

for a simulation period of only 22 quarters contrasted to the more demanding 40-quarter simulation period in this paper.

17. The value of the $F(27,114)$ ratio based on estimating separate equations for 1962:Q1-1983:Q4 and 1984:Q1-2005:Q2 is 1.25, compared to a 5 percent critical F value of 1.55.

18. See also Tetlow and Ironside (2005) for an analysis of changes in the slope used in the Federal Reserve's FRB/US model. 


\section{Where Did the Productivity Growth Go? Page 22}

\section{Estimating the TV-NAIRU}

The time-varying NAIRU or "TVN" is estimated in equation (3) simultaneously with the inflation equation (2) above. In the process of estimating the NAIRU, the coefficients are forced to sum to unity. For each set of variables, there is a different TVN. For instance, when supplyshock variables are omitted, the TVN soars to 8 percent in the mid-1970s, since this is the only way the inflation equation can "explain" why inflation was so high in that decade. However, when the full set of supply shocks is included in the inflation equation, the TVN is quite stable.

As explained above, the NAIRU can either be so smooth as to be a constant, or so jumpy as to explain all the residual variation in the inflation equation. Rather than estimate the gain ratio for the Kalman smoother, either through a maximum likelihood estimate or by using the Stock-Watson median unbiased estimator, we impose a gain ratio of $0.0125 .{ }^{19}$ This was chosen as a compromise level that would allow the NAIRU to vary over time, yet also removed all negative serial correlation. ${ }^{20}$ The TVN series associated with our basic inflation equation for the PCE deflator is displayed in figure 5. It remains within a narrow band between 1962 and 1988 but then drifts downwards until it reaches 5 percent in 1995.

Thus we concur with the general consensus that the TVN is currently roughly in the vicinity of

19. See Stock and Watson (1996). Specifically, we used a Quandt likelihood ratio statistic and drew our estimate of the gain ratio from their table 3 .

20. We reject negative serial correlation in the TVN, because the basic idea of the NAIRU is to reflect the gradual evolution of frictions in labor and product markets. For a further discussion of the "smoothness issue," see Gordon (1998, pp. 311-12). 


\section{Where Did the Productivity Growth Go? Page 23}

5.0 percent. ${ }^{21}$ For historical continuity, Figure 5 also displays the TVN that was estimated for the PCE deflator in Gordon (1998, Figure 1, p. 312). Our current specification yields a TVN that is about half a percentage point below the 1998 "Goldilocks" specification for most of the sample period, but the 1998 version of the TVN declines more rapidly in the mid-1990s and is virtually the same as our current version in 1997-98.

\section{Adding the Wage Equation and Closing the Model}

It has long been recognized that any factors that affect prices could also affect wages.

This can be supported from a wage aspiration framework, from the basic supply shock perspective set out above, or from a purely statistical argument.22 Our baseline wage equation is therefore estimated with identical explanatory variables as the equation for prices. We will then add a feedback term that allows wages and prices dynamically to interact with each other.

The explanatory variable in the wage equations, rather than being simply compensation per hour, is the change in trend unit labor cost, which is defined as the growth in compensation per hour minus trend productivity:

$$
\left(w-\theta^{*}\right)_{t}=d(L)\left(w-\theta^{*}\right)_{t-1}+f(L)\left(U_{t}-U^{N_{t}}\right)+g(L) z_{t}+e_{t}
$$

This is identical to the inflation equation (2) above, except that we have replaced the inflation rate $(p)$ with the change in trend unit labor cost, that is, the change in nominal compensation per hour $(w)$ minus the change in trend productivity growth $\left(\theta^{*}\right)$. One of the reasons for using the

21. The standard error for the estimate of the NAIRU is 0.92 . 


\section{Where Did the Productivity Growth Go? Page 24}

change in trend unit labor cost, rather than actual unit labor cost, is that it removes the added variance associated with highly volatile changes in measured productivity growth. Throughout this paper, we focus on trend productivity growth; it is used as the explanatory variable in Tables 3 and 4 and is subtracted from wage change to form the dependent variable of the wage equations.

\section{Closing the Model}

How was the post-1995 revival of productivity growth divided between slower inflation and faster growth in nominal compensation per hour? We start with the definition of the change in trend labor's share $(t l s)$ as the change in the nominal wage rate $(w)$ minus the trend in productivity growth $\left(\theta^{*}\right)$ minus the inflation rate $(p)$.

$$
t l_{t}=\left(w-\theta^{*}\right)_{t}-p_{t}
$$

How does the change in trend labor's share enter into the price and wage change equations? A remarkable feature of the inflation equation ( 2 above) is that wages do not matter for the determination of inflation. An equally remarkable feature of the wage equation (4 above) is that prices do not matter for the determination of wage changes. Loosening these restrictions allows us to develop symmetric price and wage change equations with mutual feedback between prices and wages, and this feedback is transmitted by the change in trend labor's share.

We begin by modifying the wage equation (4) to allow changes in trend unit labor cost

22. Sims (1987) argued that equations with wages and prices as alternative dependent variables are 


\section{Where Did the Productivity Growth Go? Page 25}

(TULC) to depend both on lagged TULC changes and lagged inflation.

$$
\begin{gathered}
\left(w-\theta^{*}\right)_{t}=d(L)\left(w-\theta^{*}\right)_{t}+h(L) p_{t-1}+f(L)\left(U_{t}-U^{N_{t}}\right)+g(L) z_{t}+e_{t} \\
\left(w-\theta^{*}\right)_{t}=[d(L)+h(L)]\left(w-\theta^{*}\right)_{t}-h(L)\left(w-\theta^{*}-p_{t}\right)+f(L)\left(U_{t}-U^{N_{t}}\right)+g(L) z_{t}+e_{t}
\end{gathered}
$$

Equation (6) is completely general in allowing any mix of lagged TULC change and lagged inflation to drive the evolution of TULC changes. Equation (7) is a simple algebraic rearrangement of equation (7) that adds and subtracts the " $h$ " coefficients multiplied by the change in TULC $\left(w-\theta^{*}\right)_{t}$. By constraining the sum of the $d$ and h coefficients, the natural rate hypothesis can be retained. Notice that the transformation brings the change in trend labor's share into the equation, as the second term multiplied by $\mathrm{h}(L)$ is the same as $t l s t$ as defined above in equation (5). An identical transformation can be applied to the price equation that adds the lagged effect of trend unit labor costs as a supply shock term and, after the same transformation, introduces the change in trend labor's share into the inflation equation. ${ }^{23}$

$$
\begin{gathered}
p_{t}=a(L) p_{t-1}+j(L)\left(w-\theta^{*}\right)_{t-1}+b(L)\left(U_{t}-U^{N_{t}}\right)+c(L) z_{t}+e_{t} \\
p_{t}=[a(L)+j(L)] p_{t-1}+j(L)\left(w-\theta^{*}-p\right){ }_{t-1}+f(L)\left(U_{t}-U_{t}^{N_{t}}\right)+g(L) z_{t}+e_{t}
\end{gathered}
$$

Notice that our final TULC change and inflation equations (7 and 9) are completely symmetric, explaining the dependent variable with a set of lagged dependent variables, the change in trend labor's share, the output gap, and supply shocks. The only difference is that the change in trend

simply alternative "rotations" of each other.

23. Equation (7) is identical to equation (8) in Gordon (1998, p. 306). That paper worked out the role of changes in trend labor's share in transmitting wage impulses and price impulses back and forth between the inflation and wage change equations, but it did not develop an adequate empirical implementation of the model. 


\section{Where Did the Productivity Growth Go? Page 26}

labor's share enters with opposite signs, negative in the TULC equation (7) and positive in the inflation equation (9).

\section{Estimated Coefficients and Simulation Performance}

Table 4 displays results from the preferred specification (9) of the inflation equation applied in columns (1) and (4) to two different inflation measures, the PCE deflator and the NFPB deflator. Then columns (2) and (5) estimate equation (7) for the change in trend unit labor cost. The biggest differences between the wage equation and the inflation equation are in the summary statistics, with a much better fit for the inflation equations. Coefficients are somewhat different in the wage equation from those in the price equations. The reaction of trend unit labor costs to the unemployment gap is somewhat smaller that that of prices, and the reactions to the medical care effect and the relative price of imports are negative rather than positive, albeit insignificant.

In Table 4 all the inflation and TULC equations include the change in trend labor's share, as required by equations (7) and (9) above, and this extra term has been entered with the first through eight lags. In all of the these equations, the sum of coefficients on lagged tls is significant and of the correct sign, positive in the inflation equations and negative in the TULC equations. The simulation errors for inflation are similar to those in the model without wage feedback, but those for trend unit labor costs are noticeably better than when the lagged tls terms are excluded.

The coefficients are subtracted in columns (3) and (6) in order to derive an equation for 


\section{Where Did the Productivity Growth Go? Page 27}

the change in trend labor's share. An interesting result in row 2 of columns (3) and (6) is that as aggregate demand improves, as represented by a decline in the unemployment gap, tls is predicted to be negative as the extra demand boosts prices more than wages. This is nothing more than the famous result of the countercyclical real wage (or negatively sloped labor demand curve) debated in the late 1930s by Keynes and his critics.

Another important implication of Table 4 is that the sum of coefficients on the lagged tls terms in line 7 , column (6), subtract to a value of -0.87 , implying that all other things being equal, the growth rate of $t l s$ will tend towards zero through an error-correction mechanism, eventually finding an equilibrium. Second, the early (lag 1) effect of a productivity acceleration (line 8) implies a fall in labor's share, and the late (lag 5) corrects some of this. The long run effect of changes in productivity is extinguished by the negative coefficient on lagged $t l s$, but in the short run the growth rate of trend labor's share is negative, and so a positive shock to trend productivity growth implies a reduction in the level of labor's share.

\section{Counterfactual Simulations}

While the coefficients on the productivity acceleration variable in Table 4 indicate that such an acceleration should cause a shift in the level of labor's share, a better way of illustrating exactly how productivity has influenced labor's share is to calculate a dynamic simulation of the price and wage equations. We will assume first that the productivity growth slowdown of the late 1960s and 1970s never occurred. Then we will assume that the post-1995 productivity acceleration never occurred. These counterfactual simulations are calculated by using the 


\section{Where Did the Productivity Growth Go? Page 28}

coefficients from the regressions over the full sample to simulate price and wage changes, first with all the variables taking on their actual values, and then alternatively with the productivity acceleration terms set to zero. The simulation that "turns off" the productivity slowdown runs from 1965:Q1 to 1980:Q1. The simulation that "turns off" the productivity revival runs from 1995:Q3 to 2005:Q2. Recall that the 1995-2005 simulation results differ from those summarized at the bottom of Tables 3 and 4, because those simulations terminated the sample period at 1995:Q2, whereas these simulations use coefficients based on the entire 1962-2005 sample period and thus would be expected to have lower mean errors.

Table 5 summarizes the results of the two simulations. The top section shows five lines of results for the NFPB deflator, the actual change, the simulated change assuming the actual behavior of the productivity growth trend acceleration variable, the counterfactual simulation that suppresses to zero the same productivity variable, the simulation error (line 1 minus 2), and the counterfactual effect of the change in trend productivity growth (line 2 minus 3 ). The middle section shows the same for the change in trend unit labor cost, and the bottom section shows the same for the change in trend labor share.

Looking horizontally, Table 6 is divided into four columns, two for each of the two simulations. The left two columns summarize results for the productivity slowdown simulation of 1965-80, and the right two columns summarize results for the productivity revival after 1995. For each simulation, there are two columns. The first displays the mean annual percentage rate of change over the the full simulation period, whereas the second identifies drift in the 


\section{Where Did the Productivity Growth Go? Page 29}

simulations by displaying the four-quarter change in the final year of each simulation.

Lines A4, B4, and C4 summarize our findings for the simulation errors in each time period. As in previous simulation results displayed earlier in the paper, the simulation results for the inflation rate are very small, with no drift at all in the final four quarters of the simulation period. For the change in TULC (the middle section), the mean errors are modest but the final year errors are higher, indicating an overprediction of TULC changes at the end of the 1965-80 simulation and a substantial underprediction at the end of the 1995-2005 simulation. The TLS change errors match those for the change in TULC, since the inflation errors are so low.

Lines A5, B5, and C5 provide the main results of this section. The mean effect over the simulation period of the $1965-80$ productivity growth slowdown was to add 1.28 percentage points to the inflation rate, 1.46 to TULC growth, and 0.18 to the change in TLS. Symmetrically, the mean effect over the simulation period of the 1995-2005 productivity growth revival was to subtract 1.19 percentage points from the inflation rate, 1.38 points from TULC growth, and 0.19 points from the change in TLS. It appears that a sustained productivity growth acceleration shifts labor's share down and a sustained productivity growth slowdown shifts labor's share up, explaining part of the sharp jump in labor's share observed in the NIPA data for 1966-71. The second and fourth columns show that these productivity effects continue to grow, so that after 15 years the post-1965 productivity growth slowdown had caused the inflation rate to be 2.68 higher than otherwise, and after 10 years the post-1995 productivity growth revival had held down the annual inflation rate by 1.7 percentage points, with even greater effects on the 


\section{Where Did the Productivity Growth Go? Page 30}

change in TULC.

Overall, these results go considerably beyond the Phillips curve literature of the past decade by developing wage equations in parallel with price equations and allowing mutual feedback between them, using the change in trend labor's share as the variable of transmission of mutual feedback. We expose the wage-price model to the demanding task of staying on track in dynamic simulations, and these yield strong responses of both wage and price change to decelerations or accelerations in productivity growth. The trend decline in productivity growth between 1965 and 1978 was a much more important contributor to high inflation in the late 1960s and the entire decade of the 1970s than is generally recognized. And the trend increase in productivity growth after 1995 was the most important single element in keeping inflation low and allowing the Federal Reserve to set short-term interest rates much lower than would otherwise have been possible.

\section{Changes in the Distribution of Income}

By definition, macro models deal with sums and averages and have nothing to say about the reasons why the average growth rate of hourly compensation is different than the median growth rate of hourly compensation. Further, the median annual earnings can grow at a different rate than median hourly earnings if annual hours behave differently for low-paid and high-paid workers, as when a recession like that of 1981-82 causes a sharp drop in annual hours for low-paid workers. 


\section{Where Did the Productivity Growth Go? Page 31}

To address differences in average and median growth rates of compensation that occur when there is a shift in the distribution of income, we need to switch from macro to micro data. This part of the paper provides new results on changes in the distribution of income from Internal Revenue Service (IRS) micro data files and compares these changes with those in the Current Population Survey (CPS), the source used by most of the literature in labor economics on issues related to income inequality. While the IRS data have numerous disadvantages that we discuss here, they have the unique advantage of allowing a microscopic look at incomes within the top 10 percent of the income distribution. While the CPS data are "top-coded", so that an income of $\$ 1$ million in a particular year may be classified only as "greater than $\$ 100,000$," the IRS data provide precise data from tax returns for all taxpayers, no matter whether their income is $\$ 100,000, \$ 1$ million, or $\$ 10$ million.

When we compare our IRS data with CPS data for the main part of the income distribution by using the conventional ratios of income in the $90^{\text {th }}$ to the $10^{\text {th }}$ percentile, we obtain similar results in the magnitude and timing of the increase in income inequality since the late 1960s. But when we go above the $90^{\text {th }}$ percentile, we find significant further increases of inequality that are missed in the CPS data. While most of our analysis focuses on wage and salary income, in order to focus on the comparison of the mean and median growth rate of labor compensation with the growth rate of productivity, our data also allow an analysis of changes in the distribution of non-labor income (rent, interest, dividends, and business income), and of total labor plus non-labor income. 


\section{Where Did the Productivity Growth Go? Page 32}

\section{Data Issues}

For every year between 1966 and 2001 that IRS has released data on income tax returns from over 100,000 filers. These returns oversample those at the very top of the distribution so that one can study the distribution at the level of the top 0.1 percent (one-tenth of one percent) or even the top 0.01 percent. ${ }^{24}$ Our examination of these tax returns over the 35 year data period is thus based on roughly 5 million observations.

Because there are minimum income requirements for filing, the data are flawed by omitting income at the bottom of the distribution earned by non-filers. We follow the method of Piketty and Saez (2003) of counting the total number of tax units in the economy by adding the total number of married couples and non-married men and women over the age of eighteen. ${ }^{25}$ Total tax units and total returns filed are reported in Table 6, where we find that tax returns have consistently accounted for over 92 percent of tax units. Given that those who do not file necessarily have very little income, and only account for five to 10 percent of the population, the data provided by the IRS micro files allow us to obtain a very complete record of incomes actually earned. Table 6 also shows how many tax units reported wage income each year, and how many hours were worked per tax unit on average. We use the hours history to

24. The oversampling is extreme at the very top, where in every year between 1966 and 2001 between 3000 and 3500 returns are sampled for the top 1/100 percent, representing about 40 percent of those returns for 1966 and about 23 percent for 2001.

25. Piketty and Saez (2003) claim that the number of married couples who file individually is insignificant. 


\section{Where Did the Productivity Growth Go? Page 33}

illustrate general trends in hours worked, and subsequently to compare IRS real compensation growth per hour to growth in output per hour. ${ }^{26}$

Income is not always faithfully reported to the IRS. Every year, the BEA publishes data comparing its estimates of the amount of income that should be reported to the IRS, and what is actually reported on tax returns. The gap between the IRS and BEA measures of adjusted gross income (AGI) ranges between 9 and 13.5 percent. For wages, because nearly all wage earners file tax returns, and because their wages are reported by their employers, this gap is smaller, and is never greater than 6 percent. ${ }^{27}$ We make no adjustments to wages for misreporting, and simply assume that misreporting is equally distributed across income levels. ${ }^{28}$ Despite the problem of misreporting, our IRS data have the advantage that most income is solidly linked to W-2, 1098, and 1099 forms, and these data are not subject to the recall bias that plagues such sample surveys as the CPS.

\section{Changes in the Distribution of Wage Income in the IRS compared to the CPS}

Our research on the income distribution can be viewed as complementary to that of Autor, Katz, and Kearney (2005), hereafter A-K-K, who provide an extensive critical survey of the large labor economics literature on the sources of increased inequality, as well as their own new results from the CPS. The top frame of Figure 6 displays the log ratio of the $90^{\text {th }}$ to the $10^{\text {th }}$

26. Juhn, Murphy, and Topel (2002) find that many former income earners have dropped out of the labor force and thus appear neither in wage data nor in our IRS tax data.

27. Park (2002), Table 3. 


\section{Where Did the Productivity Growth Go? Page 34}

percentile (P90/P10) in three data sets. From A-K-K we display the log P90/P10 ratio for average hourly earnings in the March CPS and alternative May "Outgoing Rotation Group" (MORG) samples, along with the log P90/P10 ratio from our IRS data. ${ }^{29}$ The two CPS measures both compare wages only for people actually working, whereas our set looks at total income for the year. Therefore people who only work part of the year may report very low wages for the full year even if their wages when they were working were much higher, and these people will have very low wages in the IRS data but relatively higher wages in the CPS data. The average IRS annual income in P10 was only about $\$ 4,000$ in 2001, while a full-time minimum wage worker would have earned roughly $\$ 10,000$.

The bottom frame of figure 6 shows the P90/P10 ratio over time, expressed as an index number with the LN equal to zero in 1973 . The three measures show surprisingly similar changes, although there are subtle differences. The IRS series exhibits all of its increase between 1980 and 1989, whereas the March CPS increase is smoother, with an increase from zero to 0.15 during 1980-89 and a further increase to 0.27 during 1989-2001. The pattern in the MORG data is almost identical, with an increase from 0.01 in 1980 to 0.16 in 1989 to 0.27 in 2001 . The fact that the two CPS measures continued to increase in the 1990s becomes important in distinguishing among different explanations of increased inequality, as we shall explore in Part VI below.

28. One is tempted to assume that misreporting is more prevalent among the rich, who have the means with which to do it legally, and the incentive to do it illegally. If this is so, then our estimates of top income shares can be viewed as a lower bound. 


\section{Where Did the Productivity Growth Go? Page 35}

A-K-K (2005) emphasize the contrast between the behavior at the bottom and top of the income distribution, as represented by changes in the P50/P10 and P90/P10 ratios. Their results for the CPS data are the same as ours for the IRS data, which are displayed in the top frame of Figure 7. There was no change in the P50/P10 ratio over the full data interval. If all of the increase in inequality was occurring above the P50 level, and not in the P50/P10 ratio, then the sharp decline in the real minimum wage in the 1980s, emphasized as a major cause by CardDiNardo 2002, could not have been important. In contrast to the stability of the P50/P10 ratio is the increase in the P90/P10 IRS ratio.

The IRS can show us what is going on inside the top 10 percent, a great advantage over the CPS. As shown in the lower frame, while the log of the P90/P10 ratio increased by 0.292 over the 1966-2001 period, the log of the P99/P10 ratio increased by 0.628 and and the log of the P99.9/P10 ratio increased by 1.047. Taking antilogs to convert these into index numbers, we have 2001 index numbers on a 1966 base equal to 134, 187, and 285, respectively. Thus we find that the limited focus on the P90/P10 ratio in the literature based on the CPS data misses the dramatic increase in inequality within the top 10 percent.

\section{The Distribution of Labor Income in the IRS Data}

We now turn to a more detailed examination of the IRS data, starting with the top section of Table 7 that summarizes the changes in the shares of the quantiles. Over time, the shares of those in the bottom 90 percent have fallen by a total of 11 percentage points, while

39. We appreciate the help of Lawrence Katz in providing these data on the 90-10 CPS ratios. 


\section{Where Did the Productivity Growth Go? Page 36}

those of the top 10 percent have risen by a total of 11 percentage points. Shown separately is the top $1 / 100$ of a percent, the share of which increased by a factor of nine from 0.2 to 1.8 percent of total wage and salary income.

While income shares are useful for comparing relative incomes, knowing the total amount of income accruing to each quantile is more helpful for analyzing changes in welfare, and particularly our central topic in this paper, the response of individual real incomes to the post-1995 revival in productivity growth. The bottom section of Table 7 displays the total real amount of wage income (in billions of 2000 dollars) going to each of our selected quantiles, and its change between 1966 and 2001.30 Of the total increase in real labor income of over 2.8 trillion dollars, less than 12 percent went to the bottom half of the income distribution..$^{31}$ More of the income change accrued to the top one percent than the entire lower 50 percent, and more accrued to the top $1 / 100$ percent than to the entire lower 20 percent. The small share going to the bottom half reflects not just growing inequality of real hourly wages, but a smaller number of hours worked at the bottom..$^{32}$

Figure 8 shows how much of the increase in real compensation between 1997 and 2001 went to each quantile. There is a lot of symmetry here. The 90-95 and 20-50 slices are

30. Every inflation-adjusted number in this section of the paper is calculated by using the PCE deflator, not any version of the CPI.

31. The $\$ 2805$ billion estimate for the total increase in real wage income matches nicely with the BEA reported change of $\$ 3080$ billion given the decline in the percentage of BEA wages reported to the IRS 32. Gottschalk-Danziger (2005, Figures 8 and 9) show that hours worked per year for those in P10 are cyclically volatile compared to those in P90. Thus much of the upsurge of earnings inequality in the deep recession of 1981-82 is an artifact due to the fact that annual earnings dropped so much relative to hourly wages in P10 but not in P90. 


\section{Where Did the Productivity Growth Go? Page 37}

approximately the same size. The slices representing the bottom 80 percent and the top 5 percent are approximately the same size (36.1 percent and 38.2 percent, respectively). The shares of wage growth in recent years are distributed approximately the same way over the past 35 years. ${ }^{33}$

The top section of Table 8 shows the actual levels of wages and salaries at each percentile, their changes between 1966 and 2001, and the skewness of the wage distribution. Since skewness is unaffected by the magnitude of the values in the distribution, it can be used as a consistent measure of changes in inequality over time. The most notable result here is that the median real wage has risen by only 11 percent in 35 years, for an average annual growth rate of 0.3 percent. Compare this to average productivity growth of 1.57 percent over the same 1966-2001 period for the entire economy, somewhat slower than the 1.74 percent growth rate for the NFPB sector. In stark contrast real income in the $99.9^{\text {th }}$ percentile grew at over 3.4 percent per year and in the $99.99^{\text {th }}$ percentile grew at over 5.6 percent per year. Skewness tells the same story, rising from 11 in 1966 to 319 in $2001 .^{34}$

Since 1966, NIPA wages and salaries have comprised a steadily smaller portion of NIPA total compensation, due to a rising share of fringe benefits. In order to correct for this, we apply

33. A careful reader might note here that tax units are not the same as households, and since there are an average of 1.3 tax units per household, it is possible that the average household might have one tax unit that is earning very little, say an eighteen year old high school senior, and one tax unit, his or her parents, that is in the upper half of the distribution and has reaped greater gains. While this is possible, it cannot apply to most households, since the average number of units per household is only 1.3, and the minimum is obviously one. 


\section{Where Did the Productivity Growth Go? Page 38}

the decline in the NIPA wage share of compensation equally to all percentiles. The middle section of Table 8 displays percentiles after having been adjusted for the change in the share of wages in total compensation, and shows that share in the last column. This raises the average annual growth rate by the same amount, 0.24 percent, in each percentile group.

Finally, the bottom section of Table 8 shows growth rates of total compensation adjusted for hours growth. In order to compare total compensation to productivity growth, we need to know how many hours each tax unit worked. We make no assumptions about the distribution of the change in hours over time, we simply show what compensation growth would have been had there been no general decline in hours per tax unit. With these adjusted growth rates, we can compare the changes in each percentile to the 1.57 percent annual change in economywide productivity between 1966 and 2001. In the bottom of Table 8, which percentiles grew at the average rate of productivity growth of 1.57 percent or at a higher rate? Our answer is that nobody below the $90^{\text {th }}$ percentile received the average rate of productivity growth. Even the $80^{\text {th }}$ percentile, after adjusting their wages upwards for fringe benefits and hours, experienced slower real hourly compensation growth.

Even if we look at the growth in the income of individual tax units, examining a separate set of IRS panel data from 1979 to 1990, the median growth rate, after accounting for changes in hours per tax unit and wages as a share of compensation, only rises by 0.34 percent per year.

34. Measured skewness is fairly volatile since it is heavily influenced by the top few observations which are many orders of magnitude above the mean, but it has unambiguously risen an enormous amount over our sample. 


\section{Where Did the Productivity Growth Go? Page 39}

This is compared to a change in median income of -0.38 percent per year, and economywide productivity growth of 1.41 percent for the 1979-90 interval. The panel data cover only a small sample of tax returns and years, but they show that even this taking this alternative source of income growth that tracks individual taxpayers over time (e.g., students who transition into adult jobs), the median does not keep up with productivity.

\section{Capital Income}

It is well known that capital (i.e., non-labor) income is less equally distributed than labor income, but did that degree of inequality increase in the 1966-2001 period? The IRS data are ideally suited to answer this question, and allow us to include five general types of non-labor income: interest, dividends, rent, business, and pension income. We exclude capital gains income, because capital gains are excluded from NIPA personal income. Unlike wages and salaries, these income sources cannot be directly mapped to NIPA personal income tables in any productive way, for two main reasons. ${ }^{35}$ One is that some income covered by the IRS, such as small business income, is not included in the NIPA. The second is that there is a larger discrepancy between IRS reported income and its NIPA equivalent for non-labor income than for wages and salaries (as discussed above).

The data on non-labor income includes many tax filers who declare losses. Since nobody would stay in business if they were losing money every year, we assume that losses are

35. The BEA does provide comparisons of BEA and IRS equivalent measures of income, but the detailed breakdowns are not available for every year, and much of the reconciliation, especially for non-labor 


\section{Where Did the Productivity Growth Go? Page 40}

not economically significant, but rather are a result of give-aways in the tax code. Further, average declared farm income is less than zero, so we completely ignore farm income. By ignoring losses, we make the assumption that year-after-year losses are not economically meaningful but rather reflect opportunities provided by the tax system for middle-income and upper-income people to shelter income from taxes. These losses are not what we mean by "poverty" and are economically different from the situation of those who earn only wage income and are in the bottom 20 percent of the distribution.

Table 9 provides data on real income for quantiles ranked by total income, including both labor and non-labor income, as contrasted to the ranking based only on labor income in Table 7. As we would expect, the ranking based on total income is much more concentrated than labor income alone. Nearly as much of the 1966-2001 real non-labor income change went to the top 0.1 percent as went to the bottom 50 percent. The next two panels decompose income into labor and non-labor income. Comparing shares of changes, the data for all three measures of income are roughly similar for the bottom 80 percent, but then diverge sharply for the top 20 percent. The top 1 and 0.1 percent have a far higher share of new non-labor income than wage income. Every other quantile takes a smaller share of non-labor income than total income. Looking at the bottom section of Table 9, we can see that common sense holds, and as one moves up the income distribution, a larger share of total income tends to be accounted for by non-labor income. Interestingly though, over time, non-wage income has worked its way 


\section{Where Did the Productivity Growth Go? Page 41}

down the income distribution. The top quantiles have taken most of new non-labor income, but the lower quantiles, especially 50-80 and 80-90, have seen a much larger percentage of their incomes accounted for by non-labor income, while for the top 5 percent, this proportion has declined. In 1966, 72 percent of the income of the top 0.1 percent came from non-labor sources. By 2001 it was only 60 percent. For the 50-80 quantile, the share rose from 10 percent to 18 percent, nearly doubling. So there are two conflicting trends. One, the majority of new nonlabor income goes to the top 10 percent of the distribution, but on the other hand, non-labor income is taking a smaller share of income at the top, and a larger share in lower quantiles.

Figure 9 shows how the distribution of gains looks for the top 10 percent in the top frame and the top 1 percent in the bottom frame. The top decile tends to take about the same share of added labor and non-labor income, but the top centile takes a much larger share of non-wage gains. It is notable how different the bars for 1979 to 1997 and 1997 to 2001 look from those for 1966 to 1979. The share of the top 10 percent in total (labor and non-labor) real income gains ranged from 33.6 percent for 1966-79, to a much higher 59.0 percent for 1979-97, to a somewhat lower 48.6 percent for 1997-2001, averaging out at 49.4 percent for 1966-2001.

\section{Lessons from the IRS Data Analysis}

At the level of comparing P90/P10 and P50/P10 ratios, the IRS data confirm the basic conclusion of other authors based on CPS data that the increase of inequality since the late 1960s has been a phenomenon of the top half of the distribution, not the bottom half. But the top-

present analysis. 


\section{Where Did the Productivity Growth Go? Page 42}

coding of the CPS data prevents a quantification of the total number of real dollars of income that are earned within the top 10 percent of the distribution, or of measurement of increased skewness within the top 10 percent, which the IRS data allow. ${ }^{36}$

A convenient way to dramatize the role of increasing skewness at the top is to decompose the two different factors that caused fully 46 percent of real income growth from 1966 to 2001 to be earned by the top 10 percent, in contrast to its much lower 25.7 percent income share in 1966. How much of this difference between 46 and 26 percent was caused by an upward movement of P90 income relative to the lower percentiles, and how much was caused by increased skewness within the top 10 percent? To answer this question, we make a calculation of the income level of each group within the top 10 percent on the counterfactual assumption that each group ratio to P90, i.e., P95/P90, P99/P90, etc., was fixed at the 1966 ratio. It is obvious from the bottom frame of Figure 7 that the income level of each group above P90 would have been lower under the counterfactual, and indeed our calculation indicates that under this condition the top 10 percent would have captured 36 percent of the real income gain over 1966-2001 instead of the actual 46 percent. Thus we conclude that almost half (10.6 points) of the extra income gain of the top 10 percent above its original 1966 income share of 25.7 percent was due to increased P90 income relative to the lower percentiles, and the other half $(9.7$

36. Gottschalk-Danziger (2005, Figure 16, p. 252) show enormous sensitivity to CPS measures of inequality to the method of top-coding. Their P90/P10 ratio in 2002 on a base of 1979=100 is roughly 140 with "unadjusted topcoding" and 118 with "Burkhauser topcoding." 


\section{Where Did the Productivity Growth Go? Page 43}

points) was due to increased skewness within the top 10 percent. This second factor represents a finding with the IRS data that the CPS data are incapable of addressing.

Another less widely known fact is that, while the top of the income distribution takes most of the non-labor income, the share of top earners' income in P95-P100 that comes from non-wage sources has declined over the years, while the share for all other groups from P0 to P95 has increased. ${ }^{37}$

Overall, our results resolve the puzzle raised at the beginning of the paper, why has growth in median real wages and real incomes lagged so far behind productivity growth when labor's share of total income has been relatively stationary? Our answer is the labor's share includes the wage and salary income of the top 10 percent who have garnered almost half the gains over 1966-2001. The stability of labor's share disguises a large gain in the part of that labor's share that is going to the top 10 percent and a decline in the part of that labor's share that is going to everyone else, including the median earner.

\section{Causes of the Increase of Income Inequality}

Our findings naturally raise questions about the interpretation of these dramatic shifts in the distribution of income that have caused median real income gains to lag so far behind

37. Our results are complementary to those of Kopczuk and Saez (2004), who in their Figure 9 show that the increase in the share of total income for the top 0.01 percent over the period 1976-2000 consists almost entirely of salary and professional income rather than income from capital and capital gains. Comparing 2000 with 1929, the share of the top 0.01 percent was similar at 3.5 percent, but a much larger share in 1929 took the form of capital income and a much smaller share the form of salaries and professional income. 


\section{Where Did the Productivity Growth Go? Page 44}

productivity growth. We start with the question of whether there is sufficient income mobility to mitigate the effects of rising inequality. If everyone's relative income were in constant motion, allowing each person to visit each percentile of the distribution, we would not be concerned about the constantly changing cast of characters in the top 10 percent or top 0.1 percent. Subsequently we will turn to controversies in the recent literature on the causes of increased inequality and suggest a different mix of causes than in recent papers.

\section{Income Mobility}

Doubts can be raised about the significance of any findings regarding income inequality that are based on a cross-section of individuals who occupy different places in the income distribution from year to year. First, there is an obvious dependence of income on age, with low incomes for youth, higher incomes in the prime earning ages, followed by zero labor income following retirement. A typical MBA student might report wage and salary income from a summer internship of $\$ 5,000$ in one tax year but report income of $\$ 120,000$ two years later and $\$ 500,000$ ten years later. Further, wage and salary incomes of taxpaying units fluctuate from year to year for many other reasons besides age and life cycle reasons, including unemployment, movement in and out of the labor force in response to childbirth or illness, and fluctuations in sales commissions and bonuses in response to changes in national, local, or individual economic circumstances. Fluctuations are even more likely in non-labor income.

How much do such factors cause our previous analysis to overstate the increase in inequality? Mishel et. al. (2005, p. 73) cite a useful analogy from Joseph Schumpeter of a hotel 


\section{Where Did the Productivity Growth Go? Page 45}

where the quality of rooms improves the higher the floor. How many people over their lifetimes occupy both basement and penthouse rooms, as contrasted to a totally immobile society in which some remain stuck in the basement all their lives while others luxuriate permanently in the penthouse?

Evidence provided by Bradbury and Katz (2002) shows clearly that there was substantial income mobility across income quintiles over decade-long periods in the 1970s, 1980s, and 1990s. It would be surprising if this were not true, given the simple life-cycle factors evident in the example of the MBA student and the complementary retirement of his or her business executive father. Examples like the MBA student account for those who started in the basement (the bottom 20 percent) in one year and wound up in the penthouse (the top 20 percent) ten years later, but this basement-to-penthouse decadal transition occurred for only 3.3 percent of basement-dwellers in 1969, 3.2 percent in 1979, and 4.3 percent in 1989. Stories like Daddy's retirement, or his Enron-like or Worldcom-like transition from the penthouse to jail, account for 5.0, 4.2, and 3.0 penthouse dwellers in 1969, 1979, and 1989, respectively. Overall, the BradburyKatz evidence shows no increase in income mobility alongside the increase in income inequality, and indeed there were small increases in the penthouse dwellers who remained in the penthouse a decade later -49.1 percent in 1969, 50.9 percent in 1979, and 53.2 percent in 1989.

In short, income mobility due to life-cycle and other reasons is a constant feature of any economy. No one person is the median taxpayer or wage-earner forever. The important fact 


\section{Where Did the Productivity Growth Go? Page 46}

about income mobility is that it takes place independently of the quite new phenomenon of increased skewness of the distribution of labor in the 1980s and 1990s. Not only are half of the penthouse dwellers still there a decade later, but the differential of opulence in the penthouse keeps increasing relative to the basement.

\section{Causes of Increased Income Inequality}

An enormous outpouring of literature has examined the increase in wage inequality since the 1960s. Here we cite several key contributions and raise questions. We divide our discussion into three parts. The first covers the recent literature on general explanations, most often "skill-biased technical change", hereafter SBTC, that attempt to explain the increase in such ratios as P90/P10 or P90/P50. The second concerns special factors operating mainly at the bottom of the income distribution. The third concerns the top of the distribution. In our view, the evolution of the income distribution reflects multiple causes, some of them independent, and we reject the tendency of some analysts to argue for a particular single cause.

The SBTC hypothesis emerges from a simple model in which two skill classes of labor are imperfect substitutes, see for instance Katz-Murphy (1992). The skilled-unskilled (S-U) wage differential depends on the evolution of relative supplies of the two groups of labor and changes in the demand for skills. Often the relative wage of college and high-school graduates is used as a proxy for the S-U differential. Because the relative quantity of college graduates has increased, particularly in the 1970s, the SBTC proponents argue that the rising S-U differential must reflect a shift in demand toward more skilled workers. 


\section{Where Did the Productivity Growth Go? Page 47}

A prominent survey by Card and DiNardo (2003) criticizes the SBTC approach on several grounds. Assuming that the dominant technical change over the past few decades has involved computers, Card-DiNardo argue that the timing is wrong. In their data, all of the increase in inequality occurs during 1980-86 while the development of computer technology either occurred steadily or was particularly concentrated in the "new economy" period of the late 1990s. They also point out that the timing is wrong in relation to aggregate productivity growth, which as we have seen in Part II was slow in the 1979-97 period when inequality increased most and revived in the mid-1990s after most of the increase of inequality had already happened. Card-DiNardo much prefer an alternative explanation, showing that there is an almost perfect negative correlation between the increase in the P90/P10 income ratio and the decline in the real minimum wage, both of these movements being concentrated in the 1980-86 period.

Beaudry-Green (2002) also question the SBTC hypothesis, treating it as an idea whose time has come and gone. In particular, they estimate for 1971-87 a SBTC equation explaining the skilled wage differential by a relative supply term and a time trend to represent technological change and then compute the predicted value for 1988-2000. The predicted value wildly overpredicts the actual differential by about 0.35 in logs.

A-K-K (2005) provide a more complex, multi-causal interpretation. First, they support a limited role for SBTC, taking the view that the evolution of the college-high school wage differential is well explained by a steady demand-driven growth in the relative demand for 


\section{Where Did the Productivity Growth Go? Page 48}

college graduates overlaid with fluctuations in the relative supply of college graduates.

Second, in their CPS data as in Figure 6 above, the increase in P90/P10 wage inequality is

relatively steady over the 1980s and 1990s and not concentrated only in the early 1980s when the drop in the real minimum wage occurred.

However, like Beaudry-Green, A-K-K also criticize a purely SBTC explanation on the ground that the increase in inequality began to plateau around 1992, whereas the new economy revival of aggregate productivity growth began around 1995. Thus they echo the skepticism based on timing of Card-DiNardo as summarized above. Second, they emphasize the difference in the magnitude of P50/P10 inequality changes (which were negligible as in Figure 7 above), and in the P90/P50 changes which were substantial and continuous. They argue for a broader conception of SBTC in which they distinguish between five types of job tasks, ranging from "routine manual" at the bottom to "non-routine analytic" and "non-routine interactive" at the top. They assign different shares of these job tasks to each decile of the wage distribution using occupational data and conclude that there has been a sharp twist in demand growth to those tasks most common in the upper three income deciles, and they view this as evidence in favor of a "polarization hypothesis." However, their broad definitions of these job tasks cover substantial shares of the population and do not explain increased skewness within the top 10 percent.

If SBTC had been a major source of the rise in inequality, then we should have observed an increase in the relative wages of those most directly skilled in the development and use of 


\section{Where Did the Productivity Growth Go? Page 49}

computers. Yet in the 1989-97 period total real compensation of CEOs increased by 100 percent, while those in occupations related to math and computer science increased only 4.8 percent and engineers decreased by 1.4 percent. $^{38}$ Europe provides perspective, because the increase in the ratio of CEO pay to average worker pay so evident in the United States has not occurred in Europe. We return below to the puzzle of rising CEO pay premia.

\section{Inequality at the Bottom: The "Great Compression" and the U-Shaped History}

A significant limitation of most of the literature on SBTC is that it limits its attention to the period since about 1970 and ignores the 50 years before that. The basic facts to be explained about income equality are not one but two, that is, not only why inequality rose after the mid1970s but why it declined from 1929 to the mid-1970s. ${ }^{39}$ Goldin and Margo (1992) have called the flattening of the income distribution during 1930-70 the "Great Compression" and attribute it to at least three events that fit neatly into this U-shaped pattern, all of which influence the effective labor supply curve and the bargaining power of labor: (1) the rise and fall of unionization, (2) the decline and recovery of immigration, and (3) the decline and recovery in the importance of international trade and the share of imports. Unions rose and declined in part because of the encouragement by government legislation in the 1930s and increasing discouragement in the postwar years. In addition, the invention of air conditioning facilitated

38. These numbers come from Mishel et. al. (1999, Table 3.50, p. 210).

39. The most vivid representation of the U-shaped historical pattern of income inequality is KopczukSaez (2004, Figure 9), which shows the income share of the top 0.01 percent and its composition across labor and capital income. This share fell from 3.7 percent in 1929 to 0.6 percent in 1976 and then rose to 3.6 percent in 2000 . 


\section{Where Did the Productivity Growth Go? Page 50}

the dispersion of employment into the Old Confederacy with their "right to work" laws, and unions were further weakened by the steady decline in the share of employment in manufacturing and mining in light of the failure of unions to organize employees in the service sector.

Partly as a result of restrictive legislation in the 1920s, and also as a result of the Great Depression and World War II, the share of immigration per year in the total population declined from 1.3 percent in 1914 to 0.02 percent in 1933, remained very low until a gradual recovery began in the late 1960s, reaching 0.48 percent (legal and illegal) in 2002.40 Competition for unskilled labor not only arrives in the form of immigration but also in the form of imports, and the decline of the import share from the 1920s to the 1950s and its subsequent recovery is a basic fact of the national accounts.

While Card-DiNardo and A-K-K raise important questions about the SBTC hypothesis, we are surprised that they miss two obvious issues. First, inequality decreased as much from the 1920 s to the 1970 s as it increased from the 1970s to now. Are we to believe that technical change over 1920-70 was "unskilled biased"? It is possible that the heyday of unionized, assembly-line manufacturing provided repetitive jobs for high-school drop-outs, but the fact that these jobs paid relatively well surely depended more on the strength of unions, and the absence of immigration and imports. Second, the SBTC hypothesis fails to explain the absence

40. Annual immigration as a share of the U. S. population is displayed in Gordon (2003, Figure 5, p. 268). 


\section{Where Did the Productivity Growth Go? Page 51}

of an increase of income in equality in Europe despite the free flow of technology across borders. ${ }^{41}$

\section{Skewness at the Top: Superstars}

Our analysis of the IRS data in Part V suggests that most of the shift in the income distribution has been from the bottom 90 percent to the top 5 percent, and especially to the top 1 percent. This is much too narrow a group to be consistent with a widespread benefit from SBTC. We argue in this section that two possibly independent phenomena are taking place at the top of the income distribution. The first is the increasing income premia being paid to "superstars," the subject of a brilliant analysis by the late Sherwin Rosen in his 1981 article "The Economics of Superstars." Rosen explains why a limited number of stars in particular fields earn most of the income, and we extend his ideas to explain why the superstar premium has been increasing. We also take an explicit look at the incomes of two classes of superstars, "power celebrities" and major league athletes. A second group that earns a larger share of income at the top are CEOs and other top corporate officers. Recent economic research provides the beginning of an analysis of CEO premia while leaving important questions unanswered.

Rosen (1981) explains extreme skewness in occupational categories dominated by superstars by particular characteristics of demand and supply. On the demand side, both

41. For the latest data on the change in inequality in the U. S. vs. European countries, see Mishel et. al. (2005, Chapter 7). For an attempt to develop theories of how European institutions distort the evolution of technical change, see Acemoglu (2002). 


\section{Where Did the Productivity Growth Go? Page 52}

market size and price per unit (the "ticket price") multiply together to form of revenue function of which the convexity implies that "small differences in talent become magnified in large earnings differences, with great magnification if the earnings-talent gradient increases sharply near the top of the scale" (Rosen, 1981, p. 846). Competition does not work to drive down these differentials - "hearing a succession of mediocre singers does not add up to a single outstanding performance" (p. 846). On the supply side, the performer exerts the same effort whether 10 or 10,000 witness the performance.

Superstars benefit from skewness, but why has the degree of skewness increased? As Rosen recognizes, successive innovations going back to the invention of the phonograph, radio, and motion pictures have increased the size of audiences who can hear a given performance, thus increasing incomes of superstars by many multiples. Thus superstars represent a particular type of SBTC that is concentrated at the very top of the income distribution, where the technological change is the development of CDs, downloaded internet music, cable television, and other forms of "audience magnification." As Rosen shows, superstars represent an equilibrium phenomenon in economics, there is no suggestions that markets do not work, and technological change feeds directly into increased premia.

A typical reaction to our use of the superstar model to explain increased skewness at the top is to react that "there aren't enough superstars." What is the size of the superstar community relative to the 13,000 IRS tax returns in the $99.99^{\text {th }}$ percentile, which in 2001 accounted for $\$ 83$ billion of income with an entry threshold of $\$ 3.2$ million? Here we report on 


\section{Where Did the Productivity Growth Go? Page 53}

incomes of a small set of entertainment superstars and a larger group of professional athletes.

But this is only the tip of the iceberg of the superstar phenomenon. Rosen himself uses examples of professional comedians, classical music artists, economics textbook authors, other authors, and lawyers, and he quotes approvingly from Marshall's Principles which uses the examples of barristers, jockeys, painters, and musicians.

An annual Forbes feature on the "The Celebrity 100" (2005) provides estimated 2004 incomes for 100 top celebrities, including superstars in the worlds of movies, music, TV, multimedia, sports, and fiction writers. The reported incomes range from $\$ 290$ million for George Lucas to a mere $\$ 1.5$ million for Amanda Bynes, a "child star." The total income accounted for is $\$ 3.1$ billion, for an average annual income of $\$ 31$ million and a median income of $\$ 25$ million. All but three of the top 100 have incomes that qualify them for the IRS $99.99^{\text {th }}$ percentile. Yet this is an underestimate of the top 100 superstar incomes, because the celebrity list is chosen based not just on income but also on indicators of fame, including numbers of magazine covers, media citations, and internet hits.

While the top-100 celebrity list leaves unknown the total incomes of other superstars in the entertainment world, we can perform a complete census of major league baseball, football, and basketball players using data maintained by USA Today. ${ }^{42}$ The 2005 total payroll for 2820 athletes was $\$ 7.0$ billion, for an average of $\$ 2.48$ million per player, a bit short of the entry level to the IRS $99.99^{\text {th }}$ percentile. Here our main interest is the contribution of these athletic salaries 


\section{Where Did the Productivity Growth Go? Page 54}

to the overall increase in skewness, and for historical issues only the baseball data source provides information going back more than five years. For the 26 continuing baseball teams which existed in 1988, the total payroll has increased from $\$ 295$ million to $\$ 1,991$ million, and the average salary has increased from $\$ 354,000$ to $\$ 2,075,287$. The inflation-adjusted increase was 8.9 percent per year compared to the 6.0 rate of real increase for the IRS top 99.99 percentile between 1987 and 2001.

Taking the 100 celebrity superstars and the athletes together, their incomes account for $\$ 10$ billion in 2004-05 compared to the $\$ 83$ billion in the IRS $99.99^{\text {th }}$ percentile in 2001 . And this excludes other sports including golf and tennis which Rosen specifically mentions as beneficiaries of media expansion, and it excludes high-earning entertainment figures below the level of the 100 celebrities. Finally, this tally excludes the celebrity lawyers (Johnnie Cochran, David Boies) and top-earning figures in professions like management consulting and investment banking, e.g., Jack Meyer who earned \$25 million annually to manage the Harvard endowment.

\section{CEOs}

Clearly a large share of the income at the very top of the income distribution is earned by CEOs and other top corporate officers. But we treat the increasing pay premia of CEOs as different than the superstar phenomena, in light of the puzzles that arise in its economic analysis. In this section we cite other sources that document the increase in relative CEO pay

42. For baseball see http://asp.usatoday.com/sports/baseball/salaries/default.aspx and similar sites for 


\section{Where Did the Productivity Growth Go? Page 55}

compared to average pay, quantify the total size of CEO compensation in a large sample of U. S. firms, and discuss alternative explanations of the increased CEO premia that doubtless contribute to increased skewness at the top of the U. S. income distribution.

The ratio of CEO pay to average worker pay increased from 27 in 1973 to 300 in the year 2000, then fell to 237 in 2001 as a result of the stock market crash. ${ }^{43}$ Including both cash and equity compensation, the 1989-2000 increase in CEO compensation grew 342 percent as compared to 5.8 percent for the median hourly wage. A basic difficulty for any equilibrium theory to explain this jump in CEO premia is that it is primarily a phenomenon of the United States and has not happened elsewhere. The ratio of CEO pay to the compensation of manufacturing production workers in 2003 was 44.0 in the United States, more than double the ratio of 19.9 in 13 other rich countries. ${ }^{44}$

Bebchuk-Grinstein (2005), hereafter B-G, provide valuable data and analysis of the CEO pay phenomenon. First, they present average pay levels for the top 5 executives in 1500 firms, the S\&P 500, the Mid Cap 400, and the Small Cap 600. The average pay in 2001 was $\$ 14.3$ million for the CEO and $\$ 31.9$ million for the top five executives, or $\$ 6.4$ million each. This is 7500 people making $\$ 6.4$ million each, compared to the IRS $99.99^{\text {th }}$ percentile that includes 13,000 people making $\$ 6.4$ million each in 2001 . Our first inference is that most of these

football and basketball.

43. Mishel et. Al. (2005), Figure $2 Y$, p. 214. Other facts in this and the next paragraph come from the same source, pp. 212-16.

44. The discrepancy between the ratio of 44 for the cross-country comparisons and the ratio of 237 in the previous paragraph for the U. S. is explained in Mishel et. Al. $(2005$, p. 216) as due to inconsistent data sources. 


\section{Where Did the Productivity Growth Go? Page 56}

executives are in the IRS $99.99^{\text {th }}$ percentile and that their total income of $\$ 48$ billion accounts for more than half of that quantile.

Does rising CEO pay reflect a reward for increasing firm size, rate of return, or growth of rate of return? B-G regressions based on 14,154 firms show that compensation of the top five executives increased during 1993-2003 by 76 percent more than can be explained by their regressions of compensation on these explanatory factors. They calculate that the ratio of topfive compensation to total earnings for a large sample of about 20,000 firms rose from 5.0 percent in 1993-95 to 12.8 percent in 2000-02.

An explanation that B-G call the "Arm's Length Bargaining Perspective" explains increased CEO pay by demand and supply, where demand depends on the value to corporations of executive services, and supply depends on alternatives for CEOs in other occupations, and the nonpecuniary aspects of the job (stress, legal risk, etc.) B-G emerge unconvinced by this model, arguing that the stock market boom of the 1990s should have increased CEO premia only temporarily, not permanently, and that income levels in alternative occupations have increased much slower than for CEOs. They also reject the view that corporate compensation committees were ignorant of the fact that stock options imposed costs on shareholders.

Their "managerial power" perspective veers further from equilibrium economics. Directors do not seek to get the best deal for shareholders. In their view the only constraint on CEOs paying themselves unlimited amounts is the "outrage constraint" which weakened in the 


\section{Where Did the Productivity Growth Go? Page 57}

1990s as rising stock markets pacified shareholders and removed this constraint. This approach comes close to being observationally equivalent to saying that CEO pay depends on stock market valuation, although the B-G regressions suggest that CEO pay has far outpaced such valuations.

While their paper is inconclusive about the merits of an "arms-length bargaining model" versus a "managerial power model," we would propose a variant of the latter called the "scratch my back model" based on an exclusive class of CEOs who determine each other's pay with relatively few market constraints. This image is conveyed by the following:

The compensation committee talks to an outside consultant who has surveys that you could drive a truck through and pay anything you want to pay ... The outside consultant talks to the HR vice president, who talks to the CEO. The CEO says what he'd like to receive. It gets to the HR person who tells the outside consultant. And it pretty well works out that the CEO gets what he's implied he thinks he deserves, so he will be respected by his or her peers. (Morgenstern, 2005, p. 1).

The Economist christens this phenomenon the "Lake Wobegon effect," because at Garrison Keillor's Lake Wobegon "all the children are above average." No corporate compensation committee wants to pay the average, they all want to pay above average and "so bosses' pay spirals upwards" (Economist, 2003).

The basic data reviewed here and the controls applied in the B-G regressions suggest that top executive compensation has spiraled up at about the same rate as the compensation of baseball players. Both the well-understood phenomenon of superstars and the puzzling case of CEOs clearly explain most of the large increase of compensation in the $99.99^{\text {th }}$ percentile relative to the $90^{\text {th }}$. A broader interpretation of technology that includes new media inventions seems 


\section{Where Did the Productivity Growth Go? Page 58}

crucial in explaining the rising skewness of superstar income, while some role for stock market valuations may help to explain the CEO puzzle, including the difference between the U. S. and Europe.

\section{Conclusion and Further Research Agenda}

This paper started as a detective story titled "Where Did the Productivity Growth Go?" The macro part of our investigation conducted a detailed search, worthy of Sherlock Holmes or Columbo, to locate the effects of the post-1995 productivity revival, with a parallel search for the effects of the post-1965 productivity growth slowdown. The micro part of our research used IRS data to shed light inside the top $99.9^{\text {th }}$ and $99.99^{\text {th }}$ percentiles and linked increased skewness at the top both to the economics of superstars and the less well-understood phenomenon of escalating CEO pay premia.

\section{The Stunning Micro Conclusion}

A basic tenet of economic science is that productivity is the seed that creates the flower of a nation's standard of living. But our results raise doubts. Our most surprising result from the large IRS micro data set is that over the entire period 1966-2001, only the top 10 percent of the income distribution enjoyed a growth rate of total real income (excluding capital gains) equal to or above the average rate of economywide productivity growth. The bottom 90 percent of the income distribution fell behind or even were left out of the productivity gains entirely.

Another way to state our main results is that the top 1 percent of the income distribution 


\section{Where Did the Productivity Growth Go? Page 59}

accounted for 21.6 percent of real total income gains during 1966-2001 and 21.3 percent during the productivity revival period 1997-2001. Still another way to describe our results is that the top one-tenth of one percent of the income distribution earned as much of the real 1997-2001 gain in wage and salary income as the bottom 50 percent.

Our results show that the dominant share of real income gains accruing to the top 10 percent and top 1 percent is almost as large for labor income as for total income. This contradicts those economists who believe that growing inequality is entirely a matter of the dominant share of wealth and capital income at the top, as for instance Philip Swagel who recently stated "It looks like the gains from the recovery haven't really filtered down... The gains have gone to owners of capital and not to workers" (quoted in Leonhardt, 2005, p. A14). It is not that all the gains went to capital and none to labor; rather, our finding is that most of the gains in labor income went to the very top percentiles.

Many previous papers have documented an increase in American income inequality over the past three decades, but most have used CPS data that - because of top-coding - has nothing to say about shifts in the income distribution within the top 10 percent of income earners. We document that the top 10 percent of wage and salary earners gained 46 percent of real income gains during 1966-2001, whereas their income share was a lower 26 percent in 1966. Of that difference between 46 and 26 percent, half is due to an increase of incomes in the $90^{\text {th }}$ percentile relative to those below the $90^{\text {th }}$, whereas the other half is due to increased inequality within the top 10 percent and especially the gains of the top 0.1 percent compared to the next 9.9 


\section{Where Did the Productivity Growth Go? Page 60}

percent.

The post-1995 productivity growth revival did not automatically signal good news for the majority of American workers and households. Indeed, to the extent that the productivity growth "explosion" of 2001-2004 was achieved by cost-cutting, layoffs, and abnormally slow employment growth (as suggested in Gordon, 2003), then the historical link between productivity growth and higher living standards falls apart. Not only have the bottom 90 percent of American workers failed to keep up with productivity growth, many have been harmed by it.

Our new data on the micro income distribution is accompanied by a review and extension of a large literature in labor economics on inequality. We conclude that there has been virtually no increase of inequality at the bottom as measured by changes in the P50/P10 ratio. The standard explanation of SBTC has some role in explaining increased inequality in the group with incomes between P50 and P90, although the literature has raised legitimate questions about the timing of the increase in skill premia and their relation, if any, with the spread of computer technology and the timing of macro productivity growth.

Because our IRS data allow a close look inside the top 10 percent right up to the $99.99^{\text {th }}$ percentile, we emphasize causes of increased inequality at the very top. We combine two separate analyses, the first of the economics of superstars where technology has broadened audiences and increased the rewards for the very best as compared to the next best. The second is of CEO compensation, where current compensation relative to average wages has increased 


\section{Where Did the Productivity Growth Go? Page 61}

by many multiples since the 1970s as had superstar income, but perhaps for different reasons. For both analyses, we collect new data and cite other papers in concluding that superstars and CEOs account for most of the income earned in the very top quantiles of the income distribution.

\section{The New Macro Analysis}

The macro analysis provides an important advance along several dimensions in the longstanding literature on inflation and wage dynamics. The most important result directly related to our topic, "where did the productivity growth go?" is that an acceleration or deceleration of the productivity growth trend alters the inflation rate by at least one-for-one in the opposite direction. This is an impact of the change in the rate of trend productivity growth and dies out if trend productivity growth stabilizes at a new level, as in 1995-2005.

Symmetrically, the post-1965 acceleration of inflation was in part caused by the infamous "productivity slowdown." Counterfactual simulations of our econometric model suggest that the 1965-80 slowdown in productivity growth boosted inflation on average by 1.3 percentage points during the 1965-80 simulation period, while the 1995-2005 revival of productivity growth held down inflation on average by 1.2 percentage points over the 1995-2005 period.

Linking the macro and micro analysis, a deceleration of inflation caused by a productivity growth revival is good news for everyone. But it does not overturn or in any way conflict with the story of this paper's micro analysis. For a bottom-group wage earner with a real income growth rate after 1995 of 0.5 percent, that real income growth rate would have been 


\section{Where Did the Productivity Growth Go? Page 62}

-0.5 percent without the productivity growth revival. For a top-group wage earner with real income growth of 4.0 percent, the absence of the productivity growth revival would have reduced that to 3.0 percent. There were no distributional consequences of the inflation impact of the productivity growth revival (and 1965-80 slowdown), yet that inflation impact made a strong contribution to macroeconomic stability and the conduct of monetary policy. 


\section{Where Did the Productivity Growth Go? Page 63}

\section{REFERENCES}

Abraham, Katherine G., Speltzer, James R., and Stewart, Jay C (1999). “Why Do Different Wage Series Tell Different Stories?" The American Economic Review, Vol. 89, No. 2, 34-39.

Acemoglu, Daron (2002). “Cross-Country Inequality Trends," NBER Working Paper 8832, March.

Atkeson, Andrew and Lee Ohanian (2001). "Are Phillips Curves Useful for Forecasting Inflation?" Federal Reserve Bank of Minneapolis Quarterly Review, Vol. 25, No. 1, 2-11.

Autor, David H., Katz, Lawrence F., and Kearney, Melissa S. (2005). “Trends in U. S. Wage Inequality: Re-assessing the Revisionists," NBER Working Paper 11627, September.

Ball, Laurence and Moffitt, Robert (2001). "Productivity Growth and the Phillips Curve," in Alan B. Krueger and Robert M Solow, eds., The Roaring Nineties: Can Full Employment Be Sustained? New York: The Russell Sage Foundation and the Century Foundation Press.

Beaudry, Paul, and Green, David A. (2002). “Changes in U. S. Wages 1976-2000: Ongoing Skill Bias or Major Technological Change?" NBER Working Paper 8787, February.

Bebchuk, Lucian and Grinstein, Yaniv (2005). "The Growth of Executive Pay," NBER Working Paper 11443, June.

Bradbury, Katherine, and Katz, Jane (2002). “Are Lifetime Incomes Growing More Unequal? Looking at New Evidence on Family Income Mobility." Regional Review: Federal Reserve Bank of Boston, vol. 12, no. 4.

Card, David, and DiNardo, John E. (2002). "Skill-Biased Technological Change and Rising Wage Inequality: Some Problems and Puzzles," Journal of Labor Economics (20, 4), 733-83.

Economist (2003). “Where's the Stick?" October 11, p. 13.

Forbes (2005). “The Celebrity 100," July 4, pp. 102-11.

Gali, Jordi, and Gertler, Mark (1999). "Inflation Dynamics: A Structural Econometric Analysis," Journal of Monetary Economics, 44: 195-222. 


\section{Where Did the Productivity Growth Go? Page 64}

and Lopez-Salido, David (2001). "European Inflation Dynamics," European Economic Review, 45(7) June: 1237-70.

Goldin, Claudia, and Margo, Robert A. (1992). "The Great Compression: The Wage Structure in the United States at Mid-Century," Quarterly Journal of Economics, 107 (February): 134.

Gordon, Robert J. (1975). "Alternative Responses of Policy to External Supply Shocks," BPEA 1:1975, 183-206.

(1977) "Can the Inflation of the 1970s Be Explained?" BPEA 1:1977, 253-77.

(1982) "Inflation, Flexible Exchange Rates, and the Natural Rate of Unemployment." In Workers, Jobs, and Inflation, edited by Martin N. Baily. Washington: Brookings, 88-152.

(1998). "Foundations of the Goldilocks Economy: Supply Shocks and the TimeVarying NAIRU," BPEA 2:1998, 297-333.

(2003). “Exploding Productivity Growth: Context, Causes, and Implications," BPEA 2:2003, 207-79.

and King, Stephen R. (1982). “The Output Cost of Disinflation in Traditional and Vector Autregressive Models," BPEA 1:1982, 205-42.

Gottschalk, Peter, and Danziger, Sheldon (2005). "Inequality of Wage Rates, Earnings, and Family Income in the United States, 1975-2002," Review of Income and Wealth, 51 (2, June): 231-55.

Herbert, Bob (2005). “The Mobility Myth,” New York Times, June 6, p. A23.

Hubbard, R. Glenn (2005). "Pay without Performance: A Market Equilibrium Critique," Journal of Corporation Law, forthcoming.

Juhn, C., Murphy, Kevin, and Topel, Robert H. (2002). “Current Unemployment, Historically Contemplated," BPEA 2001:1, 79-136.

Katz, Lawrence F., and Murphy, Kevin M. (1992). “Changes in Relative Wages, 1963-1987: Supply and Demand Factors," Quarterly Journal of Economics, 107 (February): 35-78.

Kopczuk, Wojciech, and Saez, Emmanuel (2004). “Top Wealth Shares in the United States, 1916- 


\section{Where Did the Productivity Growth Go? Page 65}

2000: Evidence from Estate Tax Returns," NBER Working Paper 10399, March.

Ledbetter, Mark (2004). "Comparison of BEA Estimates of Personal Income and IRS Estimates of Adjusted Gross Income," Survey of Current Business, November, 9-14.

Leonhardt, David (2005). “U. S. Poverty Rate Was Up Last Year," New York Times, August 31, p. A1.

Mishel, Lawrence, Bernstein, Jared, and Allegretto, Sylvia (2005). The State of Working America 2004/2005. Ithaca and London: Cornell University Press.

Morgenstern, Gretchen (2005). “How to Slow Runaway Executive Pay," New York Times, business section, October 23, p. 1.

Park, Thae S. (2002). "Comparison of BEA Estimates of Personal Income and IRS Estimates of Adjusted Gross Income: New Estimates for 2000 and Revised Estimates for 1999," Survey of Current Business, 82 (11, November), 13-20.

Piketty, Thomas and Saez, Emmanuel (2003). "Income Inequality in the United States, 19131998," Quarterly Journal of Economics 118: 1-39.

Rosen, Sherwin (1981). “The Economics of Superstars." American Economic Review 71:5, 845-58.

Samuelson, Paul A., and Solow, Robert M. (1960). "Analytical Aspects of Anti-Inflation Policy," American Economic Review Papers and Proceedings, 50:2 (May), 177-94.

Sims, Christopher A. (1997). “Comment," BPEA, 1:1987, 117-20.

Staiger, Douglas, Stock, James H., and Watson, Mark W. (1997). "The NAIRU, Unemployment, and Monetary Policy," Journal of Economic Perspectives 11 (Winter): 33-49.

(2001). "Prices, Wages, and the U. S. NAIRU in the 1990s," in Alan B. Krueger and Robert M Solow, eds., The Roaring Nineties: Can Full Employment Be Sustained? New York: The Russell Sage Foundation and the Century Foundation Press. pp. 3-60.

Stock, James H., and Watson, Mark W. (1996). "Asymptotically Median Unbiased Estimation of Coefficient Variance in a Time Varying Parameter Model," NBER Technical Working Paper No. 201.

Tetlow, Robert J, and Ironside, Brian (2005). "Real-time Model Uncertainty in the United States: 


\section{Where Did the Productivity Growth Go? Page 66}

the Fed from 1996-2003." http://ssrn.com/abstract=701423.

Uchitelle, Louis (2005). “Were the Good Old Days That Good?” New York Times, July 3, p. C1. 


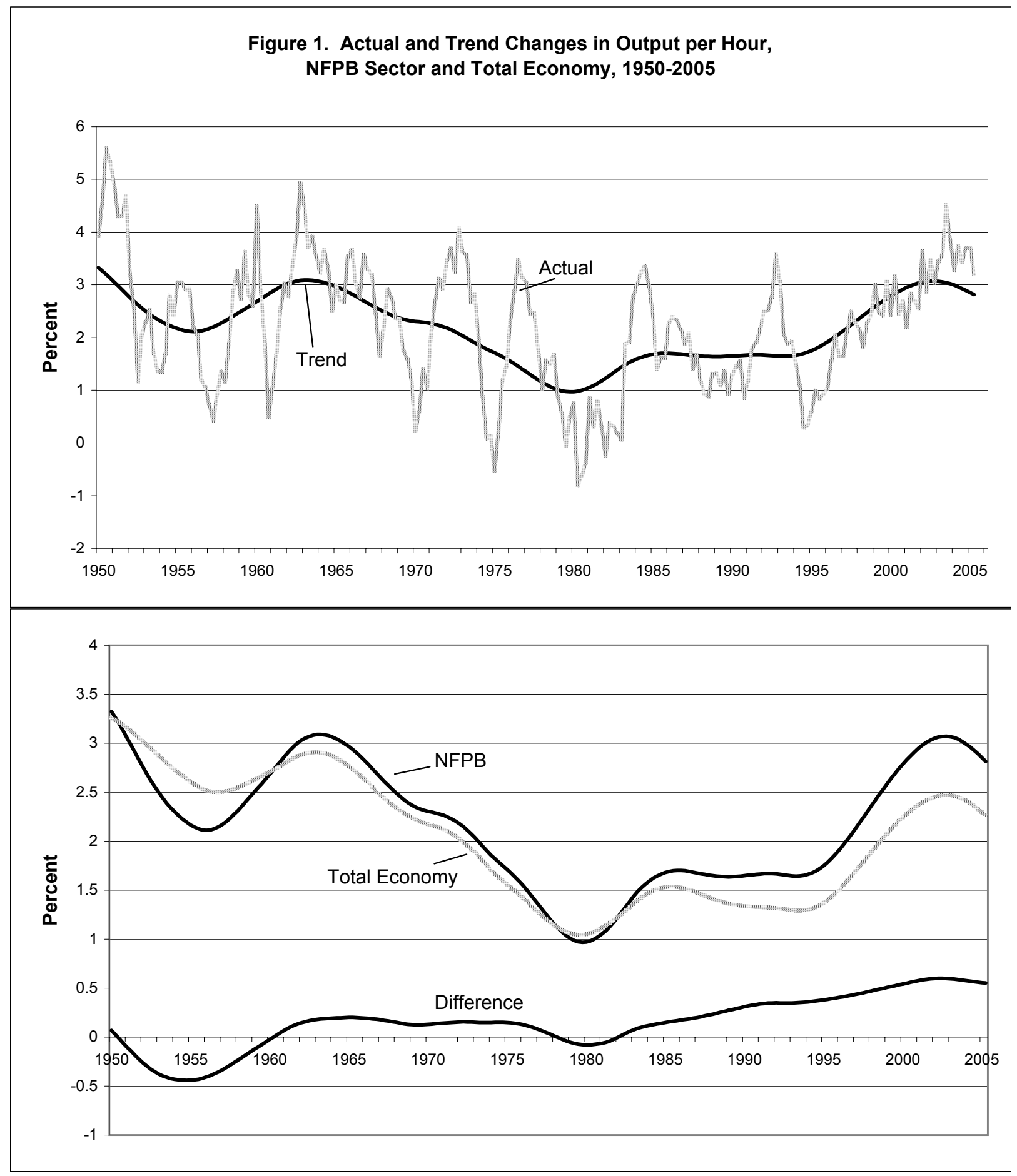




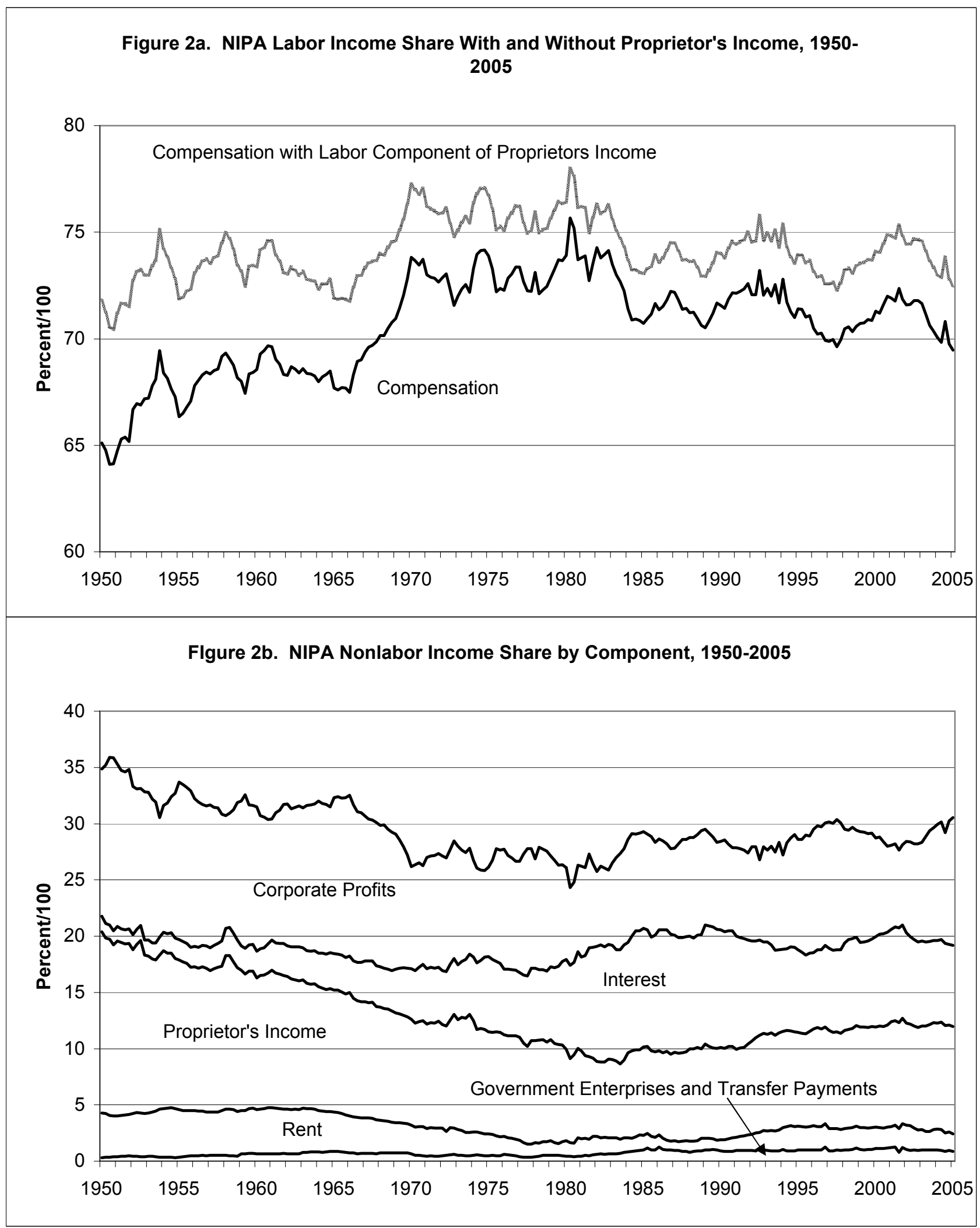


Figure 3. Productivity Acceleration

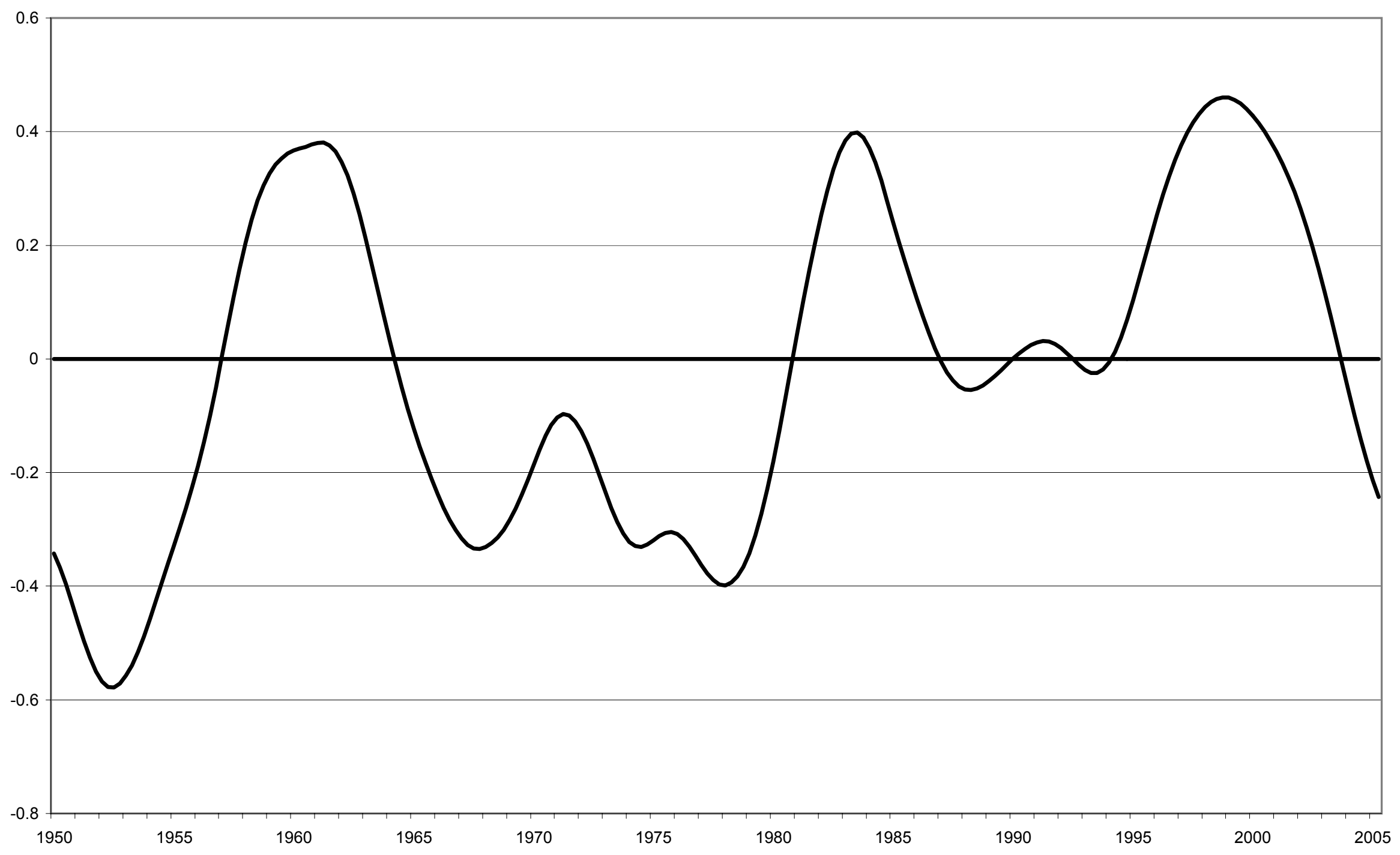


Figure 4. Four-quarter Changes in Actual and Simulated Values of PCE Deflator, 1984-2005

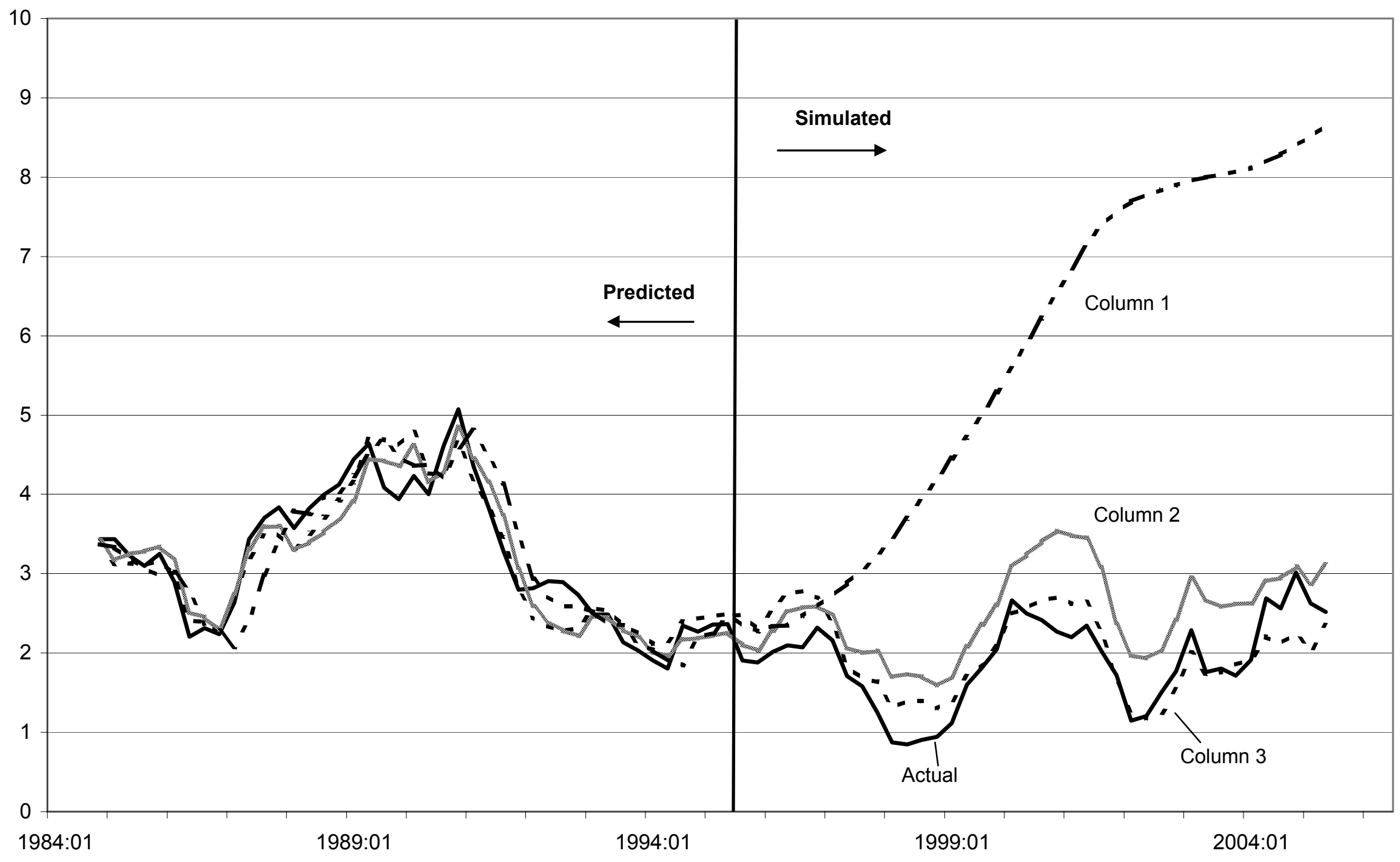


Figure 5. Time-Varying NAIRU, 1998 and Current Version, 1962-2005

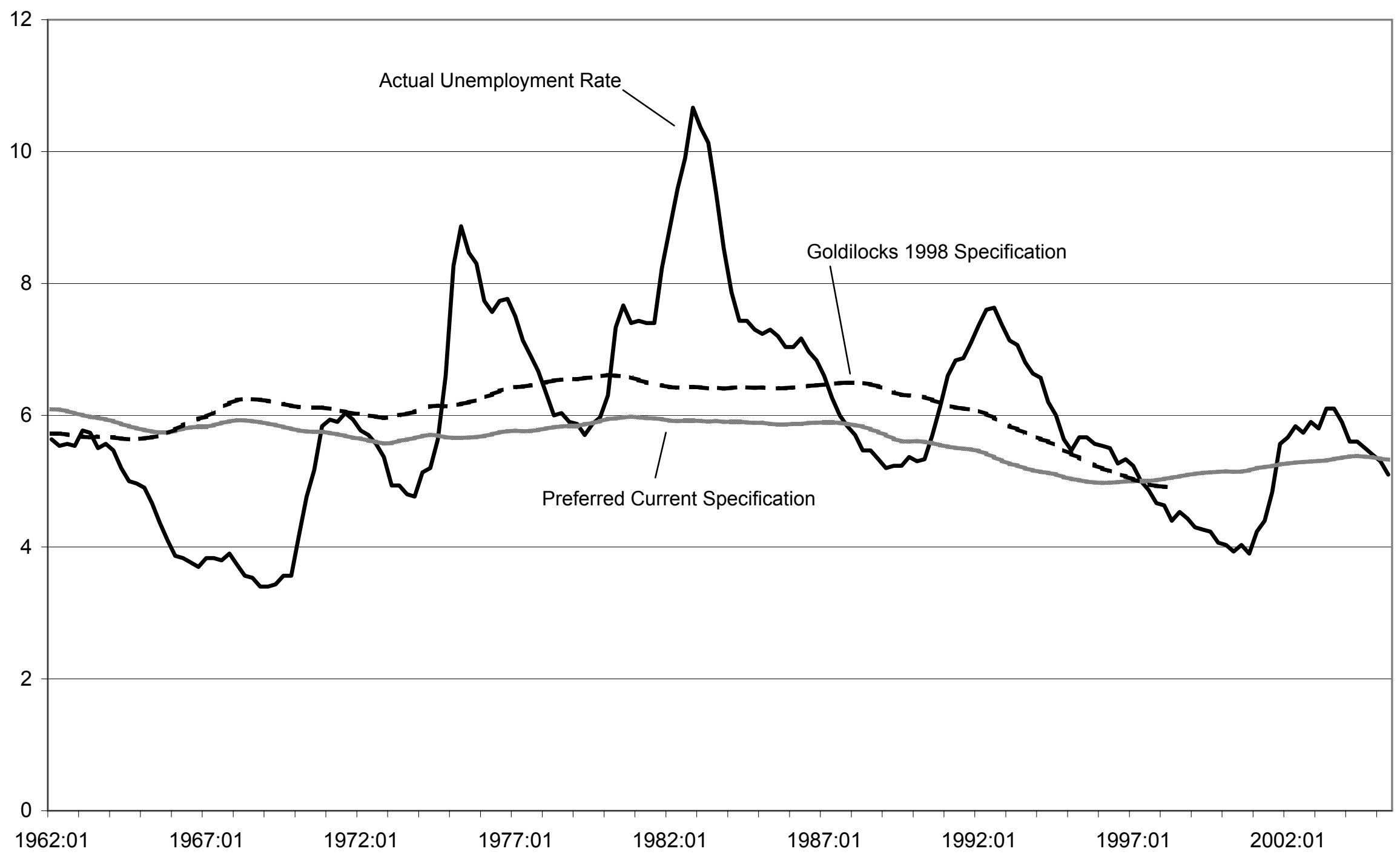


Figure 6: Log Ratios of 90th to 10th Percentiale in 3 alternative Data Sets, and Index Numbers of Ratios, 1966-2001
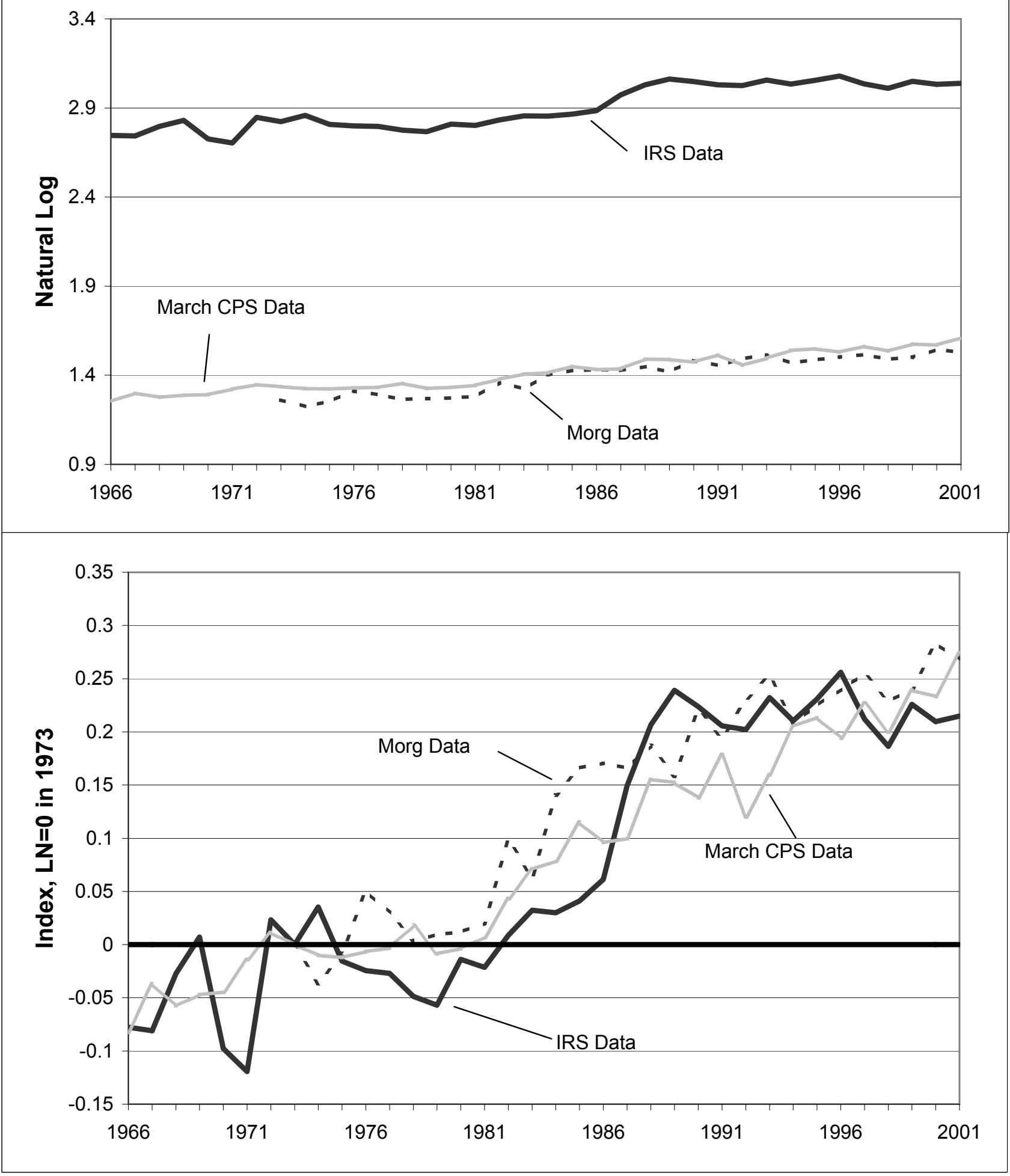


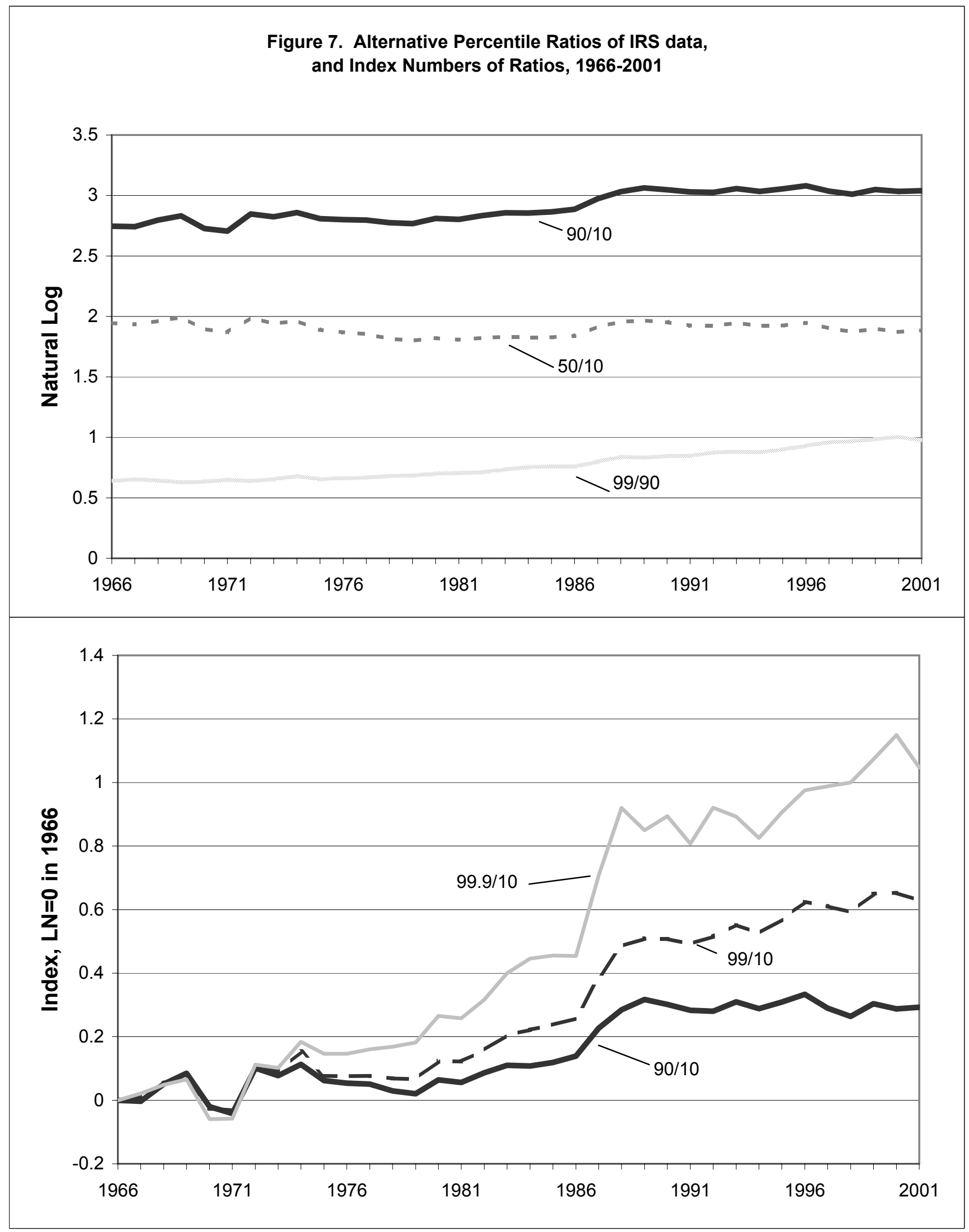


Figure 8. Share of Growth in Real Wages and Salaries, 1997-2001

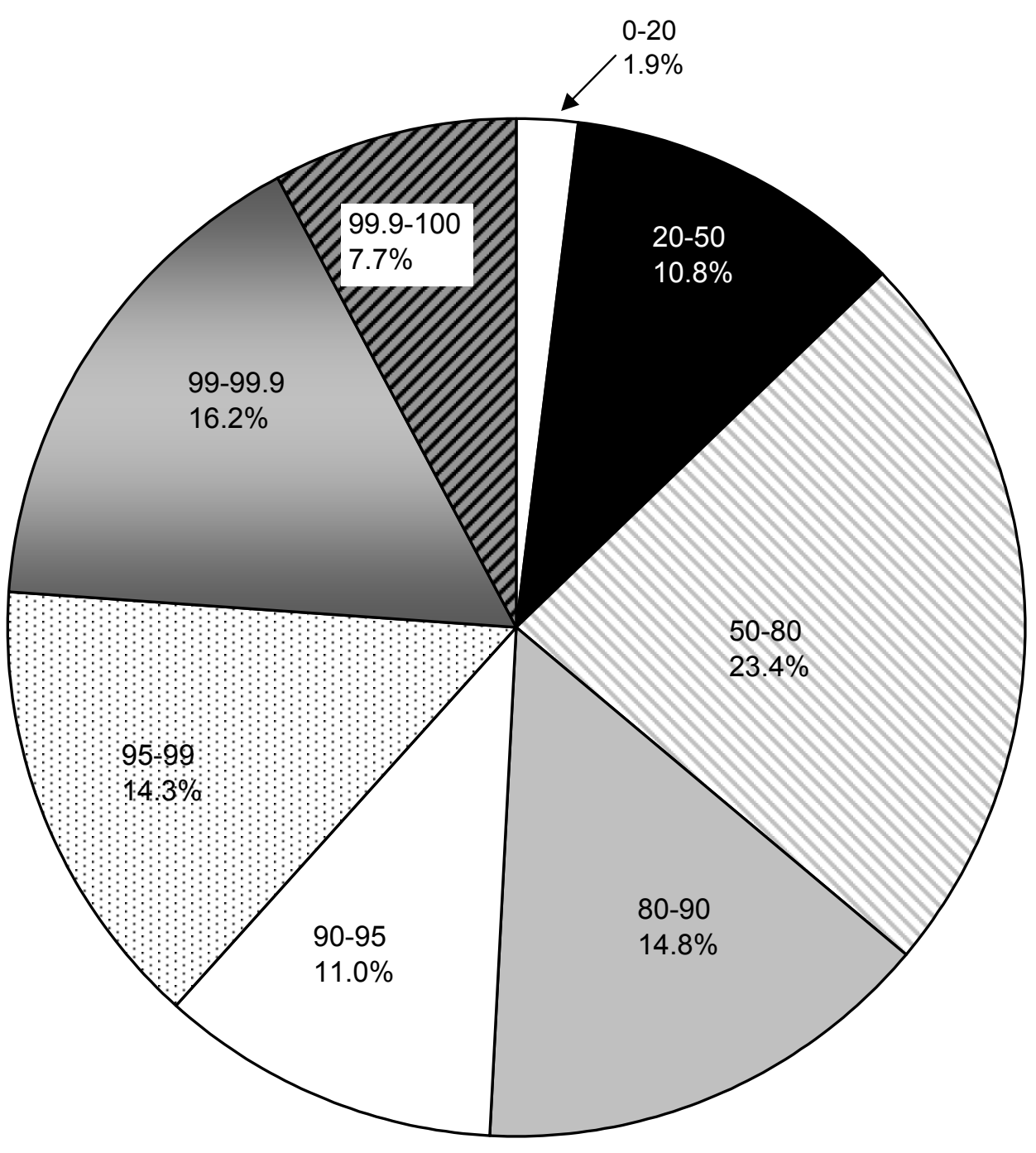


Figure 9.

Share of Top 10 Percent in Increase of Real Income, \$2000

Selected Intervals, 1966-2001

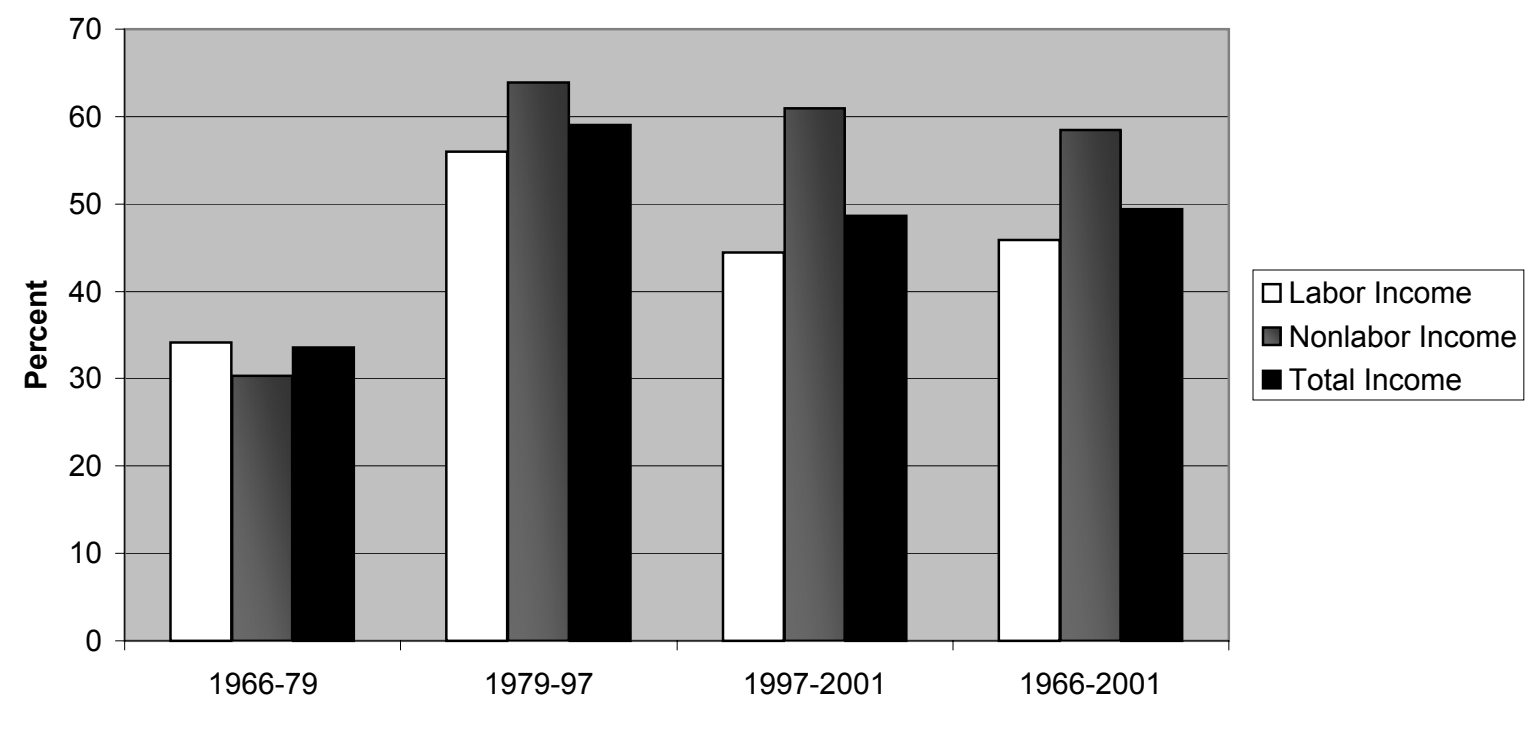

Share of Top 1 Percent in Increase of Real Income, $\$ \mathbf{2 0 0 0}$

Selected Intervals, 1966-2001

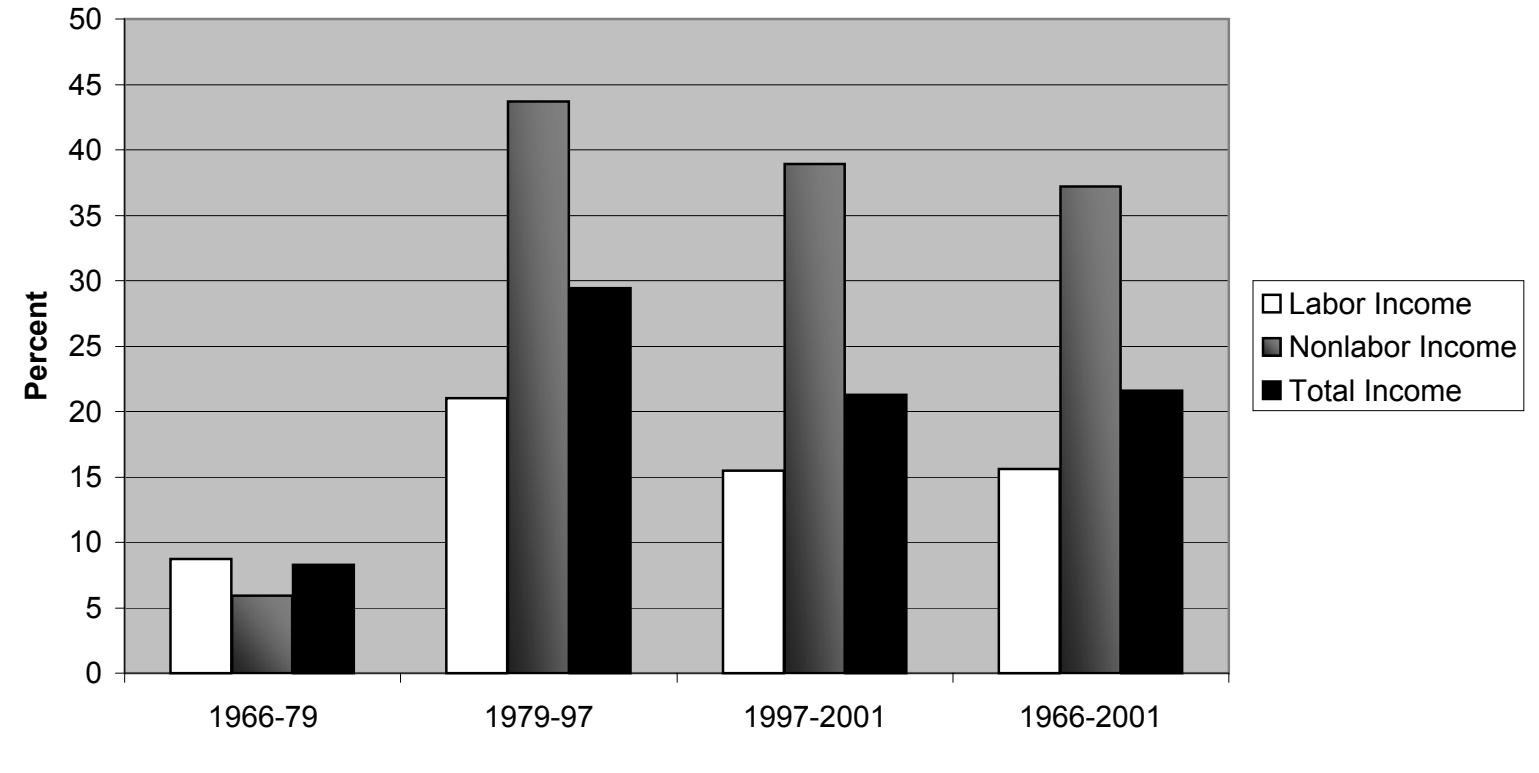




\begin{tabular}{|c|c|c|c|c|c|c|c|c|c|}
\hline \multicolumn{10}{|c|}{$\begin{array}{c}\text { Table } 1 \\
\begin{array}{c}\text { Annual Growth Rates of Output per Hour, Compensation per Hour and Labor's Share of Income } \\
\text { by Sector, Selected Intervals, 1954:Q4 - 2005:Q1 }\end{array}\end{array}$} \\
\hline & \multirow[b]{2}{*}{$\begin{array}{c}\text { 1954:Q4- } \\
\text { 1963:Q2 } \\
\end{array}$} & \multirow[b]{2}{*}{$\begin{array}{c}\text { 1963:Q2- } \\
\text { 1972:Q1 } \\
\end{array}$} & \multirow[b]{2}{*}{$\begin{array}{c}\text { 1972:Q1- } \\
\text { 1979:Q1 }\end{array}$} & \multirow[b]{2}{*}{$\begin{array}{c}1979: Q 1- \\
1987: Q 4 \\
\end{array}$} & \multirow[b]{2}{*}{$\begin{array}{c}1987: Q 4- \\
1997: Q 4 \\
\end{array}$} & \multirow[b]{2}{*}{$\begin{array}{l}\text { 1997:Q4- } \\
\text { 2005:Q1 } \\
\end{array}$} & \multirow{2}{*}{$\begin{array}{l}\text { Entire } \\
\text { Period } \\
\text { 1954:Q4- } \\
\text { 2005:Q1 }\end{array}$} & \multicolumn{2}{|c|}{ Addendum } \\
\hline & & & & & & & & $\begin{array}{l}\text { 1997:Q4- } \\
\text { 2001:Q1 }\end{array}$ & $\begin{array}{l}2001: Q 1 \\
\text { 2005:Q1 }\end{array}$ \\
\hline \multicolumn{10}{|l|}{ Output per Hour } \\
\hline Total Economy & 2.56 & 2.12 & 1.57 & 1.36 & 1.32 & 2.48 & 1.92 & 2.10 & 2.78 \\
\hline Private Business & 2.83 & 2.54 & 1.88 & 1.61 & 1.65 & 3.12 & 2.29 & 2.54 & 3.58 \\
\hline Non-Farm & 2.48 & 2.53 & 1.76 & 1.38 & 1.64 & 3.07 & 2.12 & 2.46 & 3.57 \\
\hline Farm & 4.80 & 5.14 & 4.04 & 6.81 & 3.36 & 4.03 & 4.71 & 4.95 & 3.28 \\
\hline Residual ("GHI") & 1.39 & 0.84 & 0.87 & 0.64 & 0.24 & 0.38 & 0.73 & 0.59 & 0.21 \\
\hline Government & 0.66 & -0.10 & -0.23 & 0.47 & -0.21 & 0.62 & 0.19 & 0.22 & 0.93 \\
\hline Households & 5.57 & 5.31 & 3.95 & 3.53 & 4.57 & 3.07 & 4.49 & 8.92 & -1.68 \\
\hline Institutions & 0.29 & 1.61 & 0.80 & 0.34 & 0.01 & 0.14 & 0.56 & 0.18 & 0.11 \\
\hline \multicolumn{10}{|c|}{ Real Compensation per Hour } \\
\hline Total Economy & 2.87 & 2.63 & 1.51 & 1.24 & 1.07 & 2.72 & 2.03 & 3.60 & 2.02 \\
\hline Private Business & 2.80 & 2.45 & 1.74 & 1.06 & 1.12 & 2.98 & 2.03 & 4.18 & 2.00 \\
\hline Residual ("GHI") & 3.07 & 3.14 & 0.81 & 1.80 & 0.88 & 1.95 & 2.01 & 1.68 & 2.17 \\
\hline Government & 3.02 & 3.01 & 0.48 & 1.75 & 0.75 & 2.03 & 1.91 & 1.41 & 2.53 \\
\hline Households & 1.92 & 0.57 & -1.09 & -2.28 & 4.65 & 0.71 & 0.92 & 4.57 & -2.43 \\
\hline Institutions & 2.57 & 4.07 & 1.10 & 2.32 & 0.88 & 2.18 & 2.27 & 2.48 & 1.94 \\
\hline \multicolumn{10}{|c|}{ Labor's Share of Income } \\
\hline Total Economy & 0.31 & 0.51 & -0.06 & -0.12 & -0.25 & 0.25 & 0.11 & 1.49 & -0.77 \\
\hline Private Business & -0.03 & -0.08 & -0.13 & -0.55 & -0.53 & -0.14 & -0.26 & 1.64 & -1.58 \\
\hline Residual ("GHI") & 1.68 & 2.30 & -0.06 & 1.16 & 0.64 & 1.57 & 1.28 & 1.09 & 1.97 \\
\hline Government & 2.37 & 3.11 & 0.71 & 1.27 & 0.96 & 1.41 & 1.72 & 1.18 & 1.59 \\
\hline Households & -3.65 & -4.74 & -5.03 & -5.81 & 0.07 & -2.36 & -3.58 & -4.35 & -0.74 \\
\hline Institutions & 2.28 & 2.46 & 0.30 & 1.98 & 0.87 & 2.04 & 1.72 & 2.30 & 1.83 \\
\hline
\end{tabular}

Source: NIPA Table 1.3.6 and unpublished hours data provided by Phyllis Otto of the BLS 


\section{Table 2}

Annual Growth Rates of Private Business Output per Hour and of Alternative Real

Wage Series, Selected Intervals, 1954:Q4 - 2005:Q1

\begin{tabular}{|c|c|c|c|c|c|c|c|c|c|c|}
\hline & $\begin{array}{l}\text { 1954:Q4- } \\
1963: Q 2 \\
\end{array}$ & $\begin{array}{l}\text { 1963:Q2- } \\
\text { 1972:Q1 } \\
\end{array}$ & $\begin{array}{l}\text { 1972:Q1- } \\
\text { 1979:Q1 } \\
\end{array}$ & $\begin{array}{l}\text { 1979:Q1- } \\
1987: Q 4 \\
\end{array}$ & $\begin{array}{l}\text { 1987:Q4- } \\
\text { 1997:Q4 } \\
\end{array}$ & $\begin{array}{l}\text { 1997:Q4- } \\
\text { 2005:Q1 } \\
\end{array}$ & $\begin{array}{c}\text { Entire } \\
\text { Period } \\
\text { 1954:Q4- } \\
\text { 2005:Q1 } \\
\end{array}$ & $\begin{array}{l}\text { 1997:Q4- } \\
\text { 2001:Q1 } \\
\end{array}$ & $\begin{array}{c}\text { Addendum } \\
\text { 2001:Q1- } \\
\text { 2005:Q1 } \\
\end{array}$ & $\begin{array}{l}\text { 1979:Q1- } \\
\text { 2005:Q1 }\end{array}$ \\
\hline Output per Hour & 2.83 & 2.54 & 1.88 & 1.61 & 1.65 & 3.12 & 2.29 & 2.54 & 3.58 & \\
\hline \multicolumn{11}{|l|}{ Deflated by GDP Deflator } \\
\hline Compensation per Hour & 2.80 & 2.45 & 1.74 & 1.06 & 1.12 & 2.98 & 2.03 & 4.18 & 2.00 & 1.32 \\
\hline Employment Cost Index & -- & -- & -- & 1.02 & 1.12 & 1.73 & -- & 1.99 & 1.51 & 1.02 \\
\hline Average Hourly Earnings & 1.52 & 1.67 & 0.07 & -0.34 & 0.57 & 1.11 & 0.80 & 2.00 & 0.39 & 0.34 \\
\hline \multicolumn{11}{|l|}{ Deflated by PCE Deflator } \\
\hline Compensation per Hour & 3.02 & 2.85 & 1.77 & 0.87 & 0.76 & 3.05 & 2.05 & 4.07 & 2.23 & 1.17 \\
\hline Employment Cost Index & -- & -- & -- & 0.83 & 0.75 & 1.80 & -- & 1.88 & 1.74 & 0.87 \\
\hline Average Hourly Earnings & 1.74 & 2.07 & 0.09 & -0.53 & 0.21 & 1.19 & 0.83 & 1.90 & 0.62 & 0.19 \\
\hline \multicolumn{11}{|l|}{$\begin{array}{l}\text { Difference in Growth Rates } \\
\text { Among Price Indexes }\end{array}$} \\
\hline PCE Deflator minus GDP Deflator & -0.22 & -0.40 & -0.02 & 0.19 & 0.36 & -0.08 & -0.02 & 0.11 & -0.23 & 0.15 \\
\hline CPI-U minus PCE Deflator & -0.14 & 0.28 & 0.60 & 0.68 & 0.42 & 0.45 & 0.38 & 0.73 & 0.22 & 0.42 \\
\hline
\end{tabular}

Source: NIPA Tables 
TABLE 3

Estimated Equations for Quarterly Changes in the PCE Deflator, 1962:Q1 to 2005:Q2

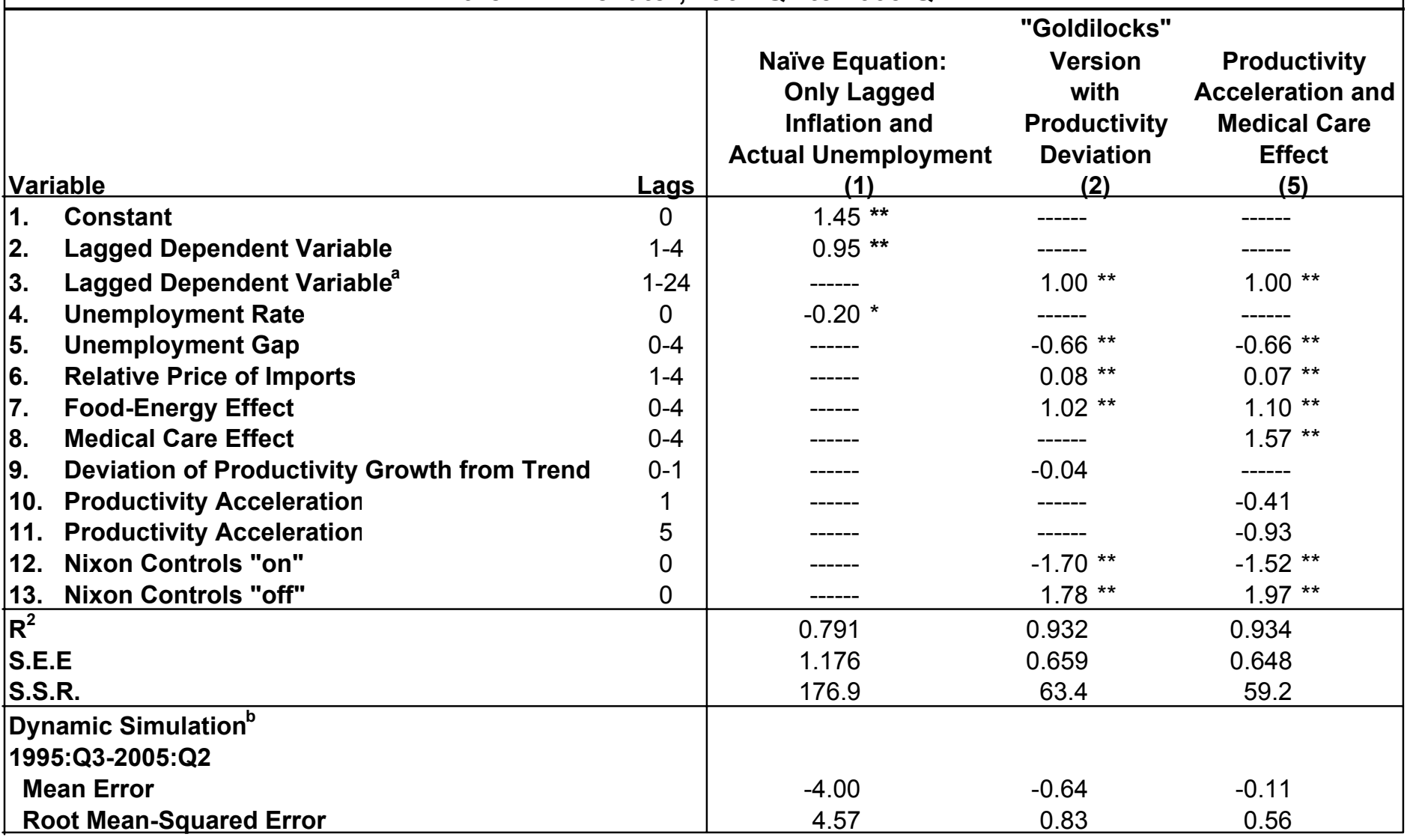

Notes: $\quad\left(^{*}\right)$ indicates that coefficient or sum of coefficients is significant at 5 percent level; $\left({ }^{* *}\right)$ at 1 percent level.

a) Lagged dependent variable is entered as the four-quarter moving average for lags $1,5,9,13,17$, and 21 , respectively

b) Dynamic simulations are based on regressions for the sample period 1962:Q1-1995:Q2 in which the coefficients on th lagged dependent variable are constrained to sum to unity. 


\begin{tabular}{|c|c|c|c|c|c|c|c|}
\hline \multicolumn{8}{|c|}{ 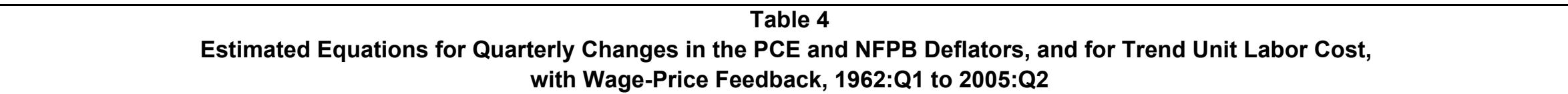 } \\
\hline Variable & Lags & $\begin{array}{l}\text { Inflation } \\
\text { (1) }\end{array}$ & $\begin{array}{l}\text { rice Equation } \\
\text { Trend Unit } \\
\text { Labor Costs } \\
\text { (2) }\end{array}$ & $\begin{array}{l}\text { Difference } \\
\begin{array}{l}(2)-(1) \\
(3)\end{array}\end{array}$ & $\begin{array}{c}\text { Inflation } \\
(4)\end{array}$ & $\begin{array}{l}\text { Price Equation } \\
\text { Trend Unit } \\
\text { Labor Costs } \\
\quad(5)\end{array}$ & $\begin{array}{l}\text { Difference } \\
(5)-(4) \\
(6)\end{array}$ \\
\hline $\begin{array}{ll}\text { 1. } & \text { Lagged Dependent Variable } \\
\text { 2. } & \text { Unemployment Gap } \\
\text { 3. } & \text { Relative Price of Imports } \\
\text { 4. } & \text { Food-Energy Effect } \\
\text { 5. } & \text { Medical Care Effect } \\
\text { 6. } & \text { PCE Trend Labor Share } \\
\text { 7. NFPB Trend Labor Share } \\
\text { 8. Productivity Acceleration } \\
\text { 9. Productivity Acceleration } \\
\text { 10. Nixon Controls "on" } \\
\text { 11. Nixon Controls "off" } \\
\end{array}$ & $\begin{array}{c}1-24 \\
0-4 \\
1-4 \\
0-4 \\
0-4 \\
1-8 \\
1-8 \\
1 \\
5 \\
0 \\
0 \\
\end{array}$ & $\begin{array}{l}0.99^{* *} \\
-0.56^{* *} \\
0.07^{*} \\
1.14^{* *} \\
1.95^{* *} \\
0.20^{* *} \\
-0.45^{* *} \\
-0.90^{* *} \\
-1.50^{* *} \\
1.95^{* *}\end{array}$ & $\begin{array}{l}1.02 * * \\
-0.32 \\
-0.09 \\
0.76 \\
-2.60 \\
-0.73 \text { * } \\
-0.25 \\
-1.17 \\
-0.30 \\
0.54 \\
\end{array}$ & $\begin{array}{c}0.24 \\
-0.16 \\
-0.38 \\
-4.55 \\
-0.93 \\
\\
0.20 \\
-0.27 \\
1.20 \\
-1.41 \\
\end{array}$ & $\begin{array}{l}0.99 * * \\
-0.43^{* *} \\
0.11^{*} \\
0.92^{* *} \\
1.80^{*} \\
0.24^{*} \\
-0.19 \\
-0.94 \\
-1.20 \\
2.29 * \\
\end{array}$ & $\begin{array}{l}1.05^{* *} \\
-0.30 \\
-0.07 \\
0.82^{*} \\
-1.63 \\
-0.63^{*} \\
-0.17 \\
-1.00 \\
-0.17 \\
0.60 \\
\end{array}$ & $\begin{array}{c}0.13 \\
-0.18 \\
-0.10 \\
-3.43 \\
\\
-0.87 \\
0.02 \\
-0.06 \\
1.03 \\
-1.69 \\
\end{array}$ \\
\hline $\begin{array}{l}\mathrm{R}^{2} \\
\text { S.E.E } \\
\text { S.S.R. }\end{array}$ & & $\begin{array}{r}0.936 \\
0.636 \\
53.8 \\
\end{array}$ & $\begin{array}{l}0.587 \\
2.020 \\
544.7\end{array}$ & & $\begin{array}{l}0.850 \\
1.070 \\
152.4\end{array}$ & $\begin{array}{l}0.580 \\
2.030 \\
549.6\end{array}$ & \\
\hline \multicolumn{8}{|l|}{$\begin{array}{l}\text { Dynamic Simulation } \\
\text { 1995:Q3-2005:Q2 }\end{array}$} \\
\hline
\end{tabular}

Notes: $\quad\left({ }^{*}\right)$ indicates that coefficient or sum of coefficients is significant at 5 percent level; $\left({ }^{* *}\right)$ at 1 percent level.

a) Lagged dependent variable is entered as the four-quarter moving average for lags $1,5,9,13,17$, and 21 , respectively.

b) Dynamic simulations are based on regressions for the sample period 1962:Q1-1995:Q2 in which the coefficients on the lagged dependent variable are constrained to sum to unity. 


\begin{tabular}{|c|c|c|c|c|}
\hline \multicolumn{5}{|c|}{$\begin{array}{c}\text { Table } 5 \\
\text { Effects of Counterfactual Simulations that Impose Zero Values on Trend Productivity Change, } \\
\text { Simulation Mean values and Four-Quarter Terminal Values, 1965:Q1-1980:Q1 and 1995:Q3-2005:Q2 }\end{array}$} \\
\hline \multirow[b]{2}{*}{ Variable and Concept } & \multicolumn{2}{|c|}{ Simulation 1965:Q1 - 1980:Q1 } & \multicolumn{2}{|c|}{ Simulation 1995:Q3 - 2005:Q2 } \\
\hline & $\begin{array}{c}\text { Mean Change } \\
\text { in Percent }\end{array}$ & $\begin{array}{c}\text { Final Quarter } \\
\text { 4-Quarter Change }\end{array}$ & $\begin{array}{c}\text { Mean Change } \\
\text { in Percent }\end{array}$ & $\begin{array}{c}\text { Final Quarter } \\
\text { 4-Quarter Change }\end{array}$ \\
\hline \multicolumn{5}{|l|}{ A. NFPB Deflator } \\
\hline 1. Actual & 5.34 & 9.39 & 1.55 & 2.31 \\
\hline 2. Factual Simulation & 5.52 & 9.41 & 1.57 & 2.32 \\
\hline 3. Counterfactual Simulation & 4.24 & 6.73 & 2.76 & 4.03 \\
\hline 4. Factual Simulation Error (1-2) & -0.18 & -0.02 & -0.02 & -0.01 \\
\hline 5. Effect of Productivity Change (2-3) & 1.28 & 2.68 & -1.19 & -1.71 \\
\hline \multicolumn{5}{|l|}{ B. Trend Unit Labor Cost } \\
\hline 1. Actual & 5.47 & 8.65 & 1.82 & 3.57 \\
\hline 2. Factual Simulation & 5.49 & 9.07 & 1.61 & 2.66 \\
\hline 3. Counterfactual Simulation & 4.03 & 6.06 & 2.99 & 4.57 \\
\hline 4. Factual Simulation Error (1-2) & -0.02 & -0.42 & 0.21 & 0.91 \\
\hline 5. Effect of Productivity Change (2-3) & 1.46 & 3.01 & -1.38 & -1.91 \\
\hline \multicolumn{5}{|l|}{ C. Change in Trend Labor Share } \\
\hline 1. Actual & 0.13 & -0.74 & 0.27 & 1.26 \\
\hline 2. Factual Simulation & -0.03 & -0.34 & 0.04 & 0.34 \\
\hline 3. Counterfactual Simulation & -0.21 & -0.67 & 0.23 & 0.54 \\
\hline 4. Factual Simulation Error (1-2) & 0.16 & -0.40 & 0.23 & 0.92 \\
\hline 5. Effect of Productivity Change (2-3) & 0.18 & 0.33 & -0.19 & -0.20 \\
\hline
\end{tabular}




\begin{tabular}{|c|c|c|c|c|c|c|}
\hline \multicolumn{7}{|c|}{$\begin{array}{c}\text { Table } 6 \\
\text { Number of Tax Units, Tax Returns, Percentage of Tax Units Filing in IRS } \\
\text { Micro Data File, and Hours per Tax Unit, Selected Years, } 1966 \text { to } 2001\end{array}$} \\
\hline Year & $\begin{array}{c}\text { Number of Tax Units } \\
\text { (thousands) }\end{array}$ & $\begin{array}{c}\text { Number of Tax Returns } \\
\text { (thousands) }\end{array}$ & $\begin{array}{l}\text { Percentage of } \\
\text { Tax Units Filing }\end{array}$ & $\begin{array}{c}\text { Percentage of Returns } \\
\text { With Wages }\end{array}$ & $\begin{array}{c}\text { Annual Hours } \\
\text { (Billions) }\end{array}$ & $\begin{array}{c}\text { Hours Per } \\
\text { Wage Return }\end{array}$ \\
\hline $\bar{~} 1966$ & 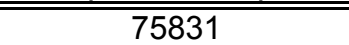 & 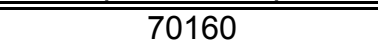 & "92.5 & "88.5 & "154 & $=2472.43$ \\
\hline 1972 & 83670 & 77573 & 92.7 & 90.2 & 161 & 2301.43 \\
\hline 1979 & 97457 & 92694 & 95.1 & 89.8 & 185 & 2229.09 \\
\hline 1987 & 112640 & 106996 & 95.0 & 85.0 & 207 & 2276.11 \\
\hline 1997 & 129532 & 122422 & 94.5 & 85.3 & 244 & 2339.35 \\
\hline 2001 & 137088 & 130255 & 95.0 & 85.4 & 254 & 2287.30 \\
\hline
\end{tabular}

Notes: This table is taken directly from Piketty and Saez (2003) except for hours data

Population and tax units estimates based on census and current population surveys (Historical

Statistics of the United States, and Statistical Abstract of the United States)

Tax units estimated as sum of married men, divorced and widowed men and women, and singles men and women aged 20 and over.

Hours data from Phyllis Otto, BLS 


\begin{tabular}{|c|c|c|c|c|c|c|c|c|}
\hline \multicolumn{9}{|c|}{$\begin{array}{l}\text { Table } 7 \\
\text { d, Wage a }\end{array}$} \\
\hline \multicolumn{9}{|c|}{ Percent Shares of Total Wage and Salary Income by Quantile } \\
\hline & 1966 & 1972 & 1979 & 1987 & 1997 & 2001 & & $\begin{array}{c}\text { Percentage Point } \\
\text { Change } \\
\end{array}$ \\
\hline $0-20$ & 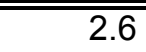 & 2.5 & 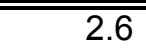 & 2.2 & 2.1 & 2.1 & & \begin{tabular}{c|}
-0.5 \\
\end{tabular} \\
\hline $20-50$ & 16.9 & 16.5 & 15.2 & 13.8 & 13.1 & 12.7 & & -4.2 \\
\hline $50-80$ & 36.0 & 35.4 & 34.5 & 32.7 & 30.9 & 29.7 & & -6.3 \\
\hline $80-90$ & 17.3 & 17.6 & 17.9 & 17.9 & 17.7 & 17.2 & & -0.1 \\
\hline $90-95$ & 10.6 & 10.9 & 11.2 & 11.6 & 12.0 & 11.8 & & 1.2 \\
\hline $95-99$ & 11.1 & 11.4 & 11.9 & 12.9 & 14.3 & 14.3 & & 3.2 \\
\hline $99-99.9$ & 4.4 & 4.5 & 5.1 & 6.2 & 5.8 & 7.6 & & 3.2 \\
\hline $99.9-100$ & 1.2 & 1.2 & 1.6 & 2.6 & 4.1 & 4.7 & & 3.5 \\
\hline $99.99-100$ & 0.2 & 0.3 & 0.4 & 0.7 & 1.5 & 1.6 & & 1.6 \\
\hline \multicolumn{9}{|c|}{ Real Amount Earned by Each Quantile (Billions of 2000 Dollars) } \\
\hline & 1966 & 1972 & 1979 & 1987 & 1997 & 2001 & Change & $\begin{array}{c}\text { Percent } \\
\text { Share of Change }\end{array}$ \\
\hline$\overline{0-20}$ & 443.2 & 54.2 & $\bar{~} 68.1$ & 67.5 & 78.0 & 91.9 & 48 & 1.7 \\
\hline $20-50$ & 283.0 & 360.1 & 398.3 & 422.3 & 488.6 & 569.1 & 286.1 & 10.2 \\
\hline $50-80$ & 603.3 & 770.3 & 900.1 & 996.2 & 1156.4 & 1330.2 & 726.9 & 25.9 \\
\hline $80-90$ & 290.5 & 382.9 & 468.2 & 546.7 & 661.5 & 771.3 & 480.8 & 17.1 \\
\hline $90-95$ & 178.1 & 237.2 & 293.3 & 353.7 & 448.6 & 530.0 & 351.9 & 12.5 \\
\hline $95-99$ & 186.0 & 248.0 & 311.2 & 394.0 & 533.5 & 640.0 & 454.0 & 16.2 \\
\hline 99-99.9 & 73.3 & 98.4 & 132.3 & 188.8 & 218.6 & 339.4 & 266.1 & 9.5 \\
\hline 99.9-100 & 19.5 & 27.0 & 41.1 & 80.3 & 152.5 & 210.1 & 190.6 & 6.8 \\
\hline 99.99-100 & 3.8 & 5.5 & 9.4 & 22.3 & 54.2 & 82.9 & 79.1 & 2.80 \\
\hline Total & 1676.9 & 2178.1 & 2612.6 & 3049.5 & 3737.7 & 4482.0 & 2805.1 & \\
\hline
\end{tabular}


Table 8

Real and Adjusted Wage and Salary Percentiles in Year 2000 Dollars, Selected Years, 1966 - 2001

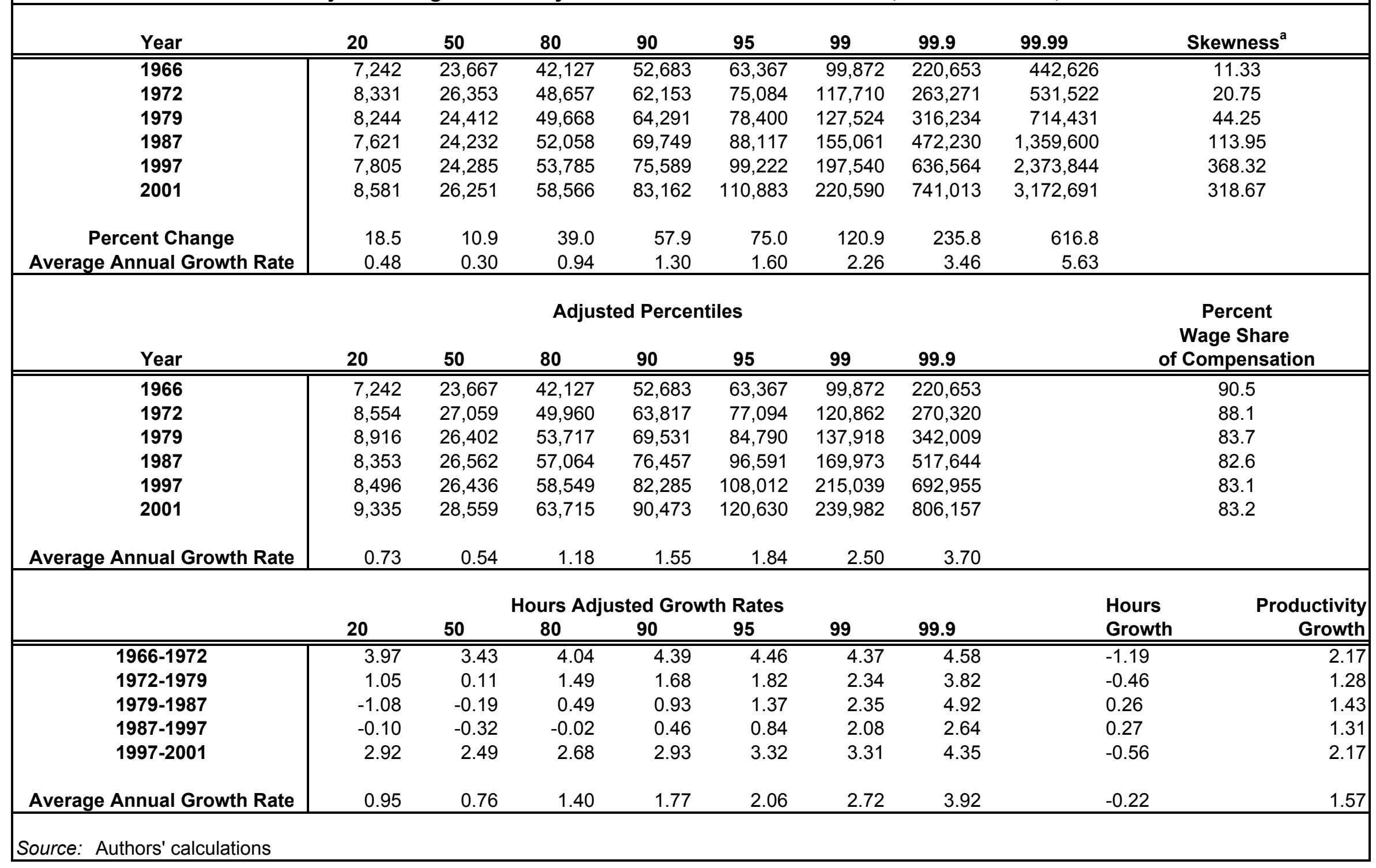




\begin{tabular}{|c|c|c|c|c|c|c|c|c|}
\hline \multicolumn{9}{|c|}{$\begin{array}{c}\text { Table } 9 \\
\text { Real Amount Earned, Sum of Labor an }\end{array}$} \\
\hline \multicolumn{9}{|c|}{ Total income } \\
\hline & 1966 & 1972 & 1979 & 1987 & 1997 & 2001 & Change & $\begin{array}{c}\text { Percent } \\
\text { Share of Change } \\
\end{array}$ \\
\hline $0-20$ & "54.3 & 699.1 & 86.7 & 83.2 & 101.6 & 118.2 & 63.9 & 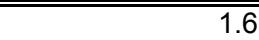 \\
\hline $20-50$ & 329.2 & 418.3 & 472.3 & 513.3 & 602.6 & 696.5 & 367.3 & 9.5 \\
\hline $50-80$ & 699.5 & 881.8 & 1044.0 & 1197.9 & 1404.5 & 1620.1 & 920.7 & 23.7 \\
\hline $80-90$ & 344.7 & 445.7 & 549.0 & 667.6 & 816.9 & 957.7 & 613.0 & 15.8 \\
\hline $90-95$ & 218.0 & 282.6 & 350.5 & 439.8 & 566.9 & 672.4 & 454.4 & 11.7 \\
\hline $95-99$ & 253.3 & 320.8 & 396.6 & 515.8 & 737.3 & 879.6 & 626.3 & 16.1 \\
\hline $99-99.9$ & 124.9 & 150.4 & 188.3 & 281.4 & 467.8 & 571.9 & 447.1 & 11.5 \\
\hline $99.9-100$ & 44.1 & 50.8 & 71.2 & 171.1 & 345.6 & 434.6 & 390.5 & 10.1 \\
\hline Total & 2068.0 & 2619.6 & 3158.6 & 3870.0 & 5043.1 & 5951.2 & 3883.3 & 100.0 \\
\hline \multicolumn{9}{|c|}{ Wage Income } \\
\hline wage & 1966 & 1972 & 1979 & 1987 & 1997 & 2001 & Change & $\begin{array}{c}\text { Percent } \\
\text { Share of Change }\end{array}$ \\
\hline 0-20 & $4 \quad 44.1$ & (57.5 & 74.6 & 9767.1 & 81.4 & 93.4 & 49.3 & 1.8 \\
\hline $20-50$ & 265.7 & 344.7 & 385.3 & 384.7 & 456.6 & 531.7 & 266.0 & 9.5 \\
\hline $50-80$ & 627.5 & 791.7 & 914.6 & 995.6 & 1155.4 & 1326.3 & 698.7 & 24.9 \\
\hline $80-90$ & 309.4 & 401.5 & 488.4 & 579.2 & 692.0 & 812.3 & 503.0 & 17.9 \\
\hline $90-95$ & 187.6 & 247.2 & 304.1 & 376.9 & 474.8 & 562.1 & 374.5 & 13.4 \\
\hline $95-99$ & 177.0 & 238.8 & 298.6 & 400.6 & 543.9 & 653.9 & 477.0 & 17.0 \\
\hline $99-99.9$ & 53.4 & 77.8 & 114.6 & 176.5 & 270.5 & 327.0 & 273.6 & 9.8 \\
\hline $99.9-100$ & 12.4 & 18.2 & 32.3 & 68.9 & 126.4 & 175.2 & 162.9 & 5.8 \\
\hline Total & 1677.0 & 2177.4 & 2612.5 & 3049.6 & 3800.9 & 4481.9 & 2805.0 & 100.0 \\
\hline \multicolumn{9}{|c|}{ Non-wage income } \\
\hline non-wage & 1966 & 1972 & 1979 & 1987 & 1997 & 2001 & Change & $\begin{array}{c}\text { Percent } \\
\text { Share of Change }\end{array}$ \\
\hline $0-20$ & 10.2 & 111.6 & 11.9 & 10.9 & 20.2 & 24.8 & 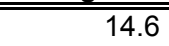 & $\overline{\overline{1.4}}$ \\
\hline $20-50$ & 63.5 & 74.0 & 87.1 & 128.6 & 145.9 & 164.9 & 101.3 & 9.4 \\
\hline $50-80$ & 71.9 & 90.1 & 129.6 & 202.4 & 249.5 & 294.3 & 222.3 & 20.6 \\
\hline $80-90$ & 35.3 & 44.2 & 60.6 & 88.4 & 124.9 & 145.4 & 110.1 & 10.2 \\
\hline $90-95$ & 30.0 & 35.1 & 46.3 & 62.9 & 92.3 & 110.5 & 80.5 & 7.5 \\
\hline $95-99$ & 76.3 & 82.0 & 98.0 & 115.3 & 193.3 & 225.6 & 149.2 & 13.8 \\
\hline $99-99.9$ & 71.5 & 72.9 & 73.8 & 104.9 & 197.3 & 245.0 & 173.5 & 16.1 \\
\hline $99.9-100$ & 31.8 & 32.3 & 38.7 & 102.1 & 219.2 & 259.4 & 227.6 & 21.1 \\
\hline Total & 390.6 & 442.1 & 546.0 & 820.4 & 1242.6 & 1469.7 & 1079.1 & 100.0 \\
\hline \multicolumn{9}{|c|}{ Non-wage Income as a Percent Share of Total Income } \\
\hline non-wage & 1966 & 1972 & 1979 & 1987 & 1997 & 2001 & Change & \\
\hline 0-20 & 18.70 & 16.75 & 13.73 & 19.15 & 19.88 & 20.96 & 2.26 & \\
\hline $20-50$ & 19.30 & 17.69 & 18.45 & 25.05 & 24.21 & 23.67 & 4.36 & \\
\hline $0-50$ & 19.22 & 17.55 & 17.72 & 24.23 & 23.59 & 23.27 & 4.06 & \\
\hline $50-80$ & 10.28 & 10.22 & 12.42 & 16.90 & 17.76 & 18.16 & 7.88 & \\
\hline $80-90$ & 10.24 & 9.91 & 11.03 & 13.24 & 15.29 & 15.18 & 4.94 & \\
\hline $90-95$ & 13.77 & 12.41 & 13.22 & 14.29 & 16.28 & 16.43 & 2.67 & \\
\hline $95-99$ & 30.14 & 25.57 & 24.71 & 22.36 & 26.22 & 25.65 & -4.49 & \\
\hline $99-99.9$ & 57.24 & 48.48 & 39.16 & 37.27 & 42.18 & 42.83 & -14.41 & \\
\hline 99.9-100 & 72.00 & 63.45 & 54.33 & 59.64 & 63.43 & 59.68 & -12.32 & \\
\hline
\end{tabular}

